\title{
RESEARCH
}

Open Access

\section{Enriched gestation activates the IGF pathway to evoke embryo-adult benefits to prevent Alzheimer's disease}

Enjie Liu ${ }^{1,4+}$, Qiuzhi Zhou ${ }^{1 \dagger}$, Ao-Ji Xie ${ }^{1}$, Mengzhu Li', Shujuan Zhang ${ }^{1}$, Hezhou Huang ${ }^{1}$, Zhenyu Liuyang ${ }^{1}$, Yali Wang ${ }^{1}$, Bingjin Liu' ${ }^{1}$ Xiaoguang Li ${ }^{1}$, Dongsheng Sun ${ }^{1}$, Yuping Wei', Xiaochuan Wang ${ }^{1}$, Qun Wang ${ }^{1}$, Dan Ke ${ }^{1}$, Xifei Yang ${ }^{3}$, Ying Yang ${ }^{1 *}$ and Jian-Zhi Wang ${ }^{1,2^{*}}$

\begin{abstract}
Background: Building brain reserves before dementia onset could represent a promising strategy to prevent Alzheimer's disease (AD), while how to initiate early cognitive stimulation is unclear. Given that the immature brain is more sensitive to environmental stimuli and that brain dynamics decrease with ageing, we reasoned that it would be effective to initiate cognitive stimulation against $A D$ as early as the fetal period.

Methods: After conception, maternal AD transgenic mice $(3 \times \operatorname{Tg} A D)$ were exposed to gestational environment enrichment (GEE) until the day of delivery. The cognitive capacity of the offspring was assessed by the Morris water maze and contextual fear-conditioning tests when the offspring were raised in a standard environment to 7 months of age. Western blotting, immunohistochemistry, real-time PCR, immunoprecipitation, chromatin immunoprecipitation (ChIP) assay, electrophysiology, Golgi staining, activity assays and sandwich ELISA were employed to gain insight into the mechanisms underlying the beneficial effects of GEE on embryos and 7-10month-old adult offspring.

Results: We found that GEE markedly preserved synaptic plasticity and memory capacity with amelioration of hallmark pathologies in 7-10-m-old AD offspring. The beneficial effects of GEE were accompanied by global histone hyperacetylation, including those at bdnf promoter-binding regions, with robust BDNF mRNA and protein expression in both embryo and progeny hippocampus. GEE increased insulin-like growth factor 1 (IGF1) and activated its receptor (IGF1R), which phosphorylates $\mathrm{Ca}^{2+} /$ calmodulin-dependent kinase IV (CaMKIV) at tyrosine sites and triggers its nuclear translocation, subsequently upregulating histone acetyltransferase (HAT) and BDNF transcription. The upregulation of IGF1 mimicked the effects of GEE, while IGF1R or HAT inhibition during pregnancy abolished the GEE-induced CaMKIV-dependent histone hyperacetylation and BDNF upregulation.

Conclusions: These findings suggest that activation of IGF1R/CaMKIV/HAT/BDNF signaling by gestational environment enrichment may serve as a promising strategy to delay AD progression.
\end{abstract}

Keywords: Alzheimer's offspring, Brain-derived neurotrophic factor, Gestational environment enrichment, Histone acetyltransferase, Insulin-like growth factor 1 receptor

\footnotetext{
* Correspondence: yingyang@hust.edu.cn; wangjz@mail.hust.edu.cn

${ }^{\dagger}$ Enjie Liu and Qiuzhi Zhou contributed equally to this work.

'Department of Pathophysiology, School of Basic Medicine and the

Collaborative Innovation Center for Brain Science, Key Laboratory of Ministry

of Education of China for Neurological Disorders, Tongji Medical College,

Huazhong University of Science and Technology, Wuhan 430030, China

Full list of author information is available at the end of the article
}

(c) The Author(s). 2019 Open Access This article is distributed under the terms of the Creative Commons Attribution 4.0 International License (http://creativecommons.org/licenses/by/4.0/), which permits unrestricted use, distribution, and reproduction in any medium, provided you give appropriate credit to the original author(s) and the source, provide a link to the Creative Commons license, and indicate if changes were made. The Creative Commons Public Domain Dedication waiver (http://creativecommons.org/publicdomain/zero/1.0/) applies to the data made available in this article, unless otherwise stated. 


\section{Background}

Emerging evidence suggests that early life events during fetal development may trigger biochemical pathways that can cause $\mathrm{AD}$ in late life [1, 2]. High-fat diet-induced maternal obesity increases the risk of developing obesity and memory deficits in offspring [3, 4]. In contrast, maternal environmental enrichment during pregnancy accelerates the development of sensory and motor circuits in the fetus $[5,6]$ and improves the emotional and attentional reactivity of offspring to stresses in adulthood [7]. Maternal swimming or treadmill running or voluntary exercise during pregnancy enhances the memory capacity of offspring [8-11]. However, these scarce findings of positive effects on offspring are exclusively limited to healthy individuals and have not been extended to disease. Thus, we aimed to investigate whether GEE could alter the onset and/or disease severity in transgenic $\mathrm{AD}$ models, a devastating disorder that is currently not curable.

Studies indicate that environmental enrichment and voluntary exercise can increase adult neurogenesis [9, $12,13]$ and promote neurotrophic and growth factors [14-16] in individuals per se exposed to the enrichment; however, the molecular mechanism underlying the parental influence on offspring is elusive. A recent study has shown that early life stress in the father improves the behavioral flexibility of offspring via epigenetic modification of histones [17]. Since the posttranslational modification of histones has a strong association with the burden of $\mathrm{AD}$ pathology $[18,19]$, we hypothesize that GEE may improve the offspring's pathology and cognitive functions by modulating histone acetylation.

In the present study, we exposed pregnant $3 \times \mathrm{Tg} \mathrm{AD}$ mothers to environment enrichment and measured the influences of GEE on the cognitive functions and AD-related pathologies in the offspring. We found that GEE preserved synaptic plasticity and spatial reference memory with attenuation of $A \beta$ and tau pathologies in the adult offspring hippocampus. We also found that GEE increased insulin-like growth factor 1 (IGF1) and activated its receptor (IGF1R), of which the latter directly binds/phosphorylates $\mathrm{Ca} 2+/$ calmodulin-dependent kinase IV (CaMKIV) to lead to the activation of histone acetyltransferase (HAT) with robust histone acetylation and BDNF production. Activation of the IGF1R/CaMKIV/HAT/BDNF pathway by GEE induced sustained chromosome remodeling, which underlies the beneficial effects of GEE.

\section{Methods}

\section{Animals and antibodies}

The $3 \times \mathrm{Tg}$ AD mice (Jackson Laboratory, Sacramento, CA, USA) were housed under a 12-h light/dark cycle with access to food and water at $25^{\circ} \mathrm{C}$. All animal studies were approved by the Ethics Committee of Tongji Medical College, Huazhong University of Science and Technology. The information for primary antibodies employed in the current study is listed in Additional file 1: Table S1.

\section{Cell culture, transfection, and drug treatment}

The cells were cultured as reported previously [20]. In brief, HEK293 cells were cultured in DMEM supplemented with $10 \%$ (vol/vol) FBS (Thermo Fisher Scientific, Waltham, MA, USA) and grown at $37^{\circ} \mathrm{C}$ in a humid atmosphere containing $5 \%(\mathrm{vol} / \mathrm{vol}) \mathrm{CO}_{2}$. CaMKIV K75E plasmids were generous gifts from Tian-ming Gao (Southern Medical University, Guangzhou, China). After repairing the mutation site, CaMKIV K75E was used to generate EGFP-CaMKIV-WT (wild type CaMKIV) by PCR (Vazyme Biotech Co., Ltd.; China). The CaMKIV mutation (tyrosine -136 and -172 into phenylalanine (Y136F, Y172F)) was generated using the Mut Express II Fast mutagenesis kit following the manufacturer's instructions (Vazyme Biotech Co., Ltd.; China). Transfection of EGFP-CaMKIV-WT, EGFP-CaMKIV-Y136F, EGFP-CaM KIV-Y172F or EGFP-CaMKIV-Y136F/Y172F in HEK293 cells was carried out using the Lipofectamine 2000 kit according to the manufacturer's instructions. To explore the effect of IGF1, the cells were treated with IGF1 $(100 \mathrm{ng} / \mu \mathrm{l}$ diluted with DMEM, 100-11, Peprotech, USA) for $2 \mathrm{~h}$. PPP

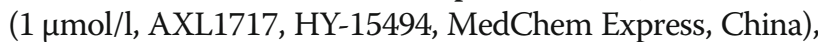
BMS-536924 (100 nmol/l, HY-10262, MedChem Express, China) or GDC-0994 (6 nmol/l, HY-15947, MedChem Express, China) was used to inhibit IGF1R or ERK. All inhibitor drugs used to treat the cell line were dissolved in DMSO (Sigma, USA), and the final concentration of the solvent was equal in all treatment groups.

\section{Environmental enrichment}

Two male and four female $3 \times \mathrm{Tg} \mathrm{AD}$ mice $(2 \mathrm{~m}$ old $)$ were mated for 2 days in each cage, and then the pregnant female mice were randomly distributed to either the home cage or GEE housing. Standard cages $(33 \mathrm{~cm} \times$ $18 \mathrm{~cm} \times 14 \mathrm{~cm}$ ) were used for the control mice, whereas large rat cages $(55 \mathrm{~cm} \times 34 \mathrm{~cm} \times 20 \mathrm{~cm})$ were used for the GEE. To increase the sense of novelty, the mice were arranged with constant access to toys of different shapes, sizes, materials and surface textures. Every 2 days, a set of 10-15 different toys was introduced into the cages to change the environment, and all the toys were moved prior to the female mice giving birth. The control group and GEE group consisted of 24 maternal female mice each, the GEE with C646 group contained 8 maternal female mice, and the GEE with BMS-536924 group had 8 maternal female mice. Female offspring were used in all fellow experiments. 


\section{In vivo drug treatment}

For inhibition of HAT in GEE, C646 $\left(5 \mathrm{mg} \mathrm{kg}^{-1} \mathrm{day}^{-1}\right.$, S7152, Selleck, China) dissolved in $0.9 \%$ saline [17] was injected intraperitoneally into the pregnant mice starting at day 5 of the GEE exposure, and the injection was continued up to embryonic day 19 (E19). The mice in home cages or GEE controls were injected with saline. The offspring were reared in the home cage for $7 \mathrm{~m}$, and then learning and memory ability were measured using the Morris water maze (MWM) or contextual fear conditioning. For inhibition of IGF1R in GEE, BMS-536924 ( $2 \mathrm{mg} \mathrm{kg}^{-1} \mathrm{day}^{-1}$, dissolved in 30\% PEG400 + 0.5\% Tween80, HY-10262, MedChem Express, China) was injected intraperitoneally into the pregnant mice starting at day 5 of the GEE exposure, and the injection was continued up to E19; the controls were injected with the same volume of solvent.

\section{MWM test}

The MWM test was performed as previously described [20]. In brief, the mice were trained to find a submerged platform hidden under water by following the constant cues outside the pool over 6 days. Before the training, we recorded the distance the mice swam in $60 \mathrm{~s}$. Next, the mice underwent a daily session of three trials per day. During each trial, mice started facing the wall of the pool and found the hidden platform in $60 \mathrm{~s}$, after which they were guided to and placed on the platform for $30 \mathrm{~s}$. The swimming path and latency to locate the hidden platform were recorded in each trial by a digital device connected to a computer. On the eighth day, the mice were allowed to swim for $60 \mathrm{~s}$ freely with the hidden platform removed to test their memory. The percent time spent in the target quadrant and the numbers of platform quadrant crosses were recorded (Chengdu Taimeng Software Co. Lid, China).

\section{Contextual fear-conditioning test}

The contextual fear-conditioning test was performed as previously described [21]. The mice were placed in the conditioning chamber for $3 \mathrm{~min}$ before an unconditioned stimulus (US) was administered, that is, a mild foot shock of $0.9 \mathrm{~mA}$ for $3 \mathrm{~s}$, on the training day. Three sequential foot shocks at 3-min intervals were applied. All chambers were cleaned with $75 \%$ alcohol to eliminate any residual odor. To assess contextual memory, the mice were placed back in the training context $24 \mathrm{~h}$ post-training for $3 \mathrm{~min}$ without an electric foot shock. The activity and freezing behavior of the animals, which was defined as a complete absence of movement, were recorded by a video tracking system (Chengdu Taimeng Software Co. Lid, China).

\section{Western blotting}

Western blotting was performed as reported previously [20]. Total proteins of hippocampi were extracted with RIPA lysis buffer (P0013B, Beyotime, China). Cytoplasm and nuclear proteins were extracted using the Nucl-Cyto-Mem Preparation Kit (P1201, Applygen Technologies Inc., China). The protein concentration was determined by the BCA method, and equal amounts of extracted proteins were separated by 10-12\% SDSpolyacrylamide gel electrophoresis (SDS-PAGE) and transferred to nitrocellulose filter membranes. Then, the nitrocellulose membranes were blocked with 5\% BSA for $1 \mathrm{~h}$ at room temperature. After blocking, the membranes were incubated with primary antibodies (Table S1). The bands were scanned and visualized using the Odyssey Infrared Imaging System (LI-COR biosciences, Lincoln, NE, USA).

\section{Immunohistochemistry}

Immunohistochemistry was performed as reported previously [21]. The mice were anesthetized and immediately transcardially perfused with normal saline, followed by $4 \%$ paraformaldehyde (PFA). Brains were removed and post-fixed for another $48 \mathrm{~h}$. Then, the brains were cryoprotected with $30 \%$ sucrose and frozen in OCT compound for cryostat sectioning. Brains were sliced coronally at a thickness of $30 \mu \mathrm{M}$ using a freezing microtome (CM1900, Leica, Germany). The brain slices were soaked in PBS-3\% $\mathrm{H}_{2} \mathrm{O}_{2}-0.5 \%$ Triton for $30 \mathrm{~min}$ and then blocked with 3\% BSA for another $30 \mathrm{~min}$. The slices were incubated with anti-BDNF antibody (SC-546, Santa Cruz, Texas, USA) overnight at $4{ }^{\circ} \mathrm{C}$, followed by a biotinylated secondary antibody for $1 \mathrm{~h}$ at $37^{\circ} \mathrm{C}$. Horseradish peroxidase-labeled antibodies were applied for $1 \mathrm{~h}$ at $37^{\circ} \mathrm{C}$ to detect the immunoreaction, and staining was performed with $\mathrm{DAB}$. The images were observed under a microscope (Nikon, 90i, Tokyo, Japan). For cell studies, the cells were cultured on coverslips and fixed with $4 \%$ paraformaldehyde for $30 \mathrm{~min}$ at room temperature, and then $1 \mu \mathrm{g} / \mathrm{ml}$ Hoechst 33258 (Sigma, St. Louis, MO, USA) was used for nuclear staining.

\section{Immunofluorescence}

The brain slices were collected as described previously [21]. The slices were incubated overnight at $4{ }^{\circ} \mathrm{C}$ with primary antibody against acetyl-histone H3 (06-599, Millipore, CA, USA) or acetyl-histone H4 (06-866, Millipore, CA, USA), followed by Oregon green 488 as the secondary antibody for $1 \mathrm{~h}$ at room temperature. Hoechst 33258 (Sigma, St. Louis, MO, USA) was used for nuclear staining. The images were observed with a laser confocal microscope (710, Zeiss, Germany). 


\section{Immunoprecipitation}

E19 hippocampi or cultured cells were homogenized on ice in lysis buffer at $4{ }^{\circ} \mathrm{C}$ for $30 \mathrm{~min}$ and centrifuged at $12,000 \mathrm{~g}$ for $10 \mathrm{~min}$. A total of $300 \mu \mathrm{l}$ of supernatants containing approximately $600 \mu \mathrm{g}$ of total proteins was incubated overnight with rotation at $4{ }^{\circ} \mathrm{C}$ with $10 \mu \mathrm{g}$ of anti-CBP, anti-CaMKIV, anti-GFP, or anti-IGF1R antibody, followed by the addition of protein $A+G$ agarose at $4{ }^{\circ} \mathrm{C}$ for $2 \mathrm{~h}$. The agarose beads were washed three times and re-suspended in $60 \mu \mathrm{l}$ of SDS loading buffer. The precipitates were analyzed by western blotting using anti-phosphoserine, anti-CBP, CaMKIV, pCaMKIV, or anti-phosphorylated tyrosine. To explore the interaction of IGF1R and CaMKIV, $600 \mu \mathrm{g}$ total proteins were incubated overnight with rotation at $4{ }^{\circ} \mathrm{C}$ with $10 \mu \mathrm{g}$ of anti-CaMKIV antibody (Santa Cruz, 136,249, USA) or anti-IGF1R antibody (Proteintech, 20,254, China), and the precipitates were analyzed by western blotting using anti-CaMKIV or IGF1R.

\section{Real-time PCR}

Total RNA was extracted using TRIzol reagent (Invitrogen, Carlsbad, CA, USA), and the reverse transcription reagent kit (RR037, Takara) was used to obtain cDNA. The published primers complementary to each $b d n f$ noncoding exon I-V were used to assay the level of expression of each individual transcript of $b d n f$ [22]. RTPCR was performed using a StepOnePlus Real-Time PCR Detection System (Life Technologies, NY, USA).

\section{Chromatin immunoprecipitation (ChIP) assay}

The ChIP analysis was performed according to published methods and Upstate Biotechnology ChIP kit (17-371, Millipore, USA) protocols using the following antibodies: anti-acetyl-histone H3 (06-599, Millipore, USA); anti-acetyl-Histone $\mathrm{H} 4$ (06-866, Millipore, USA) and mouse immunoglobulin-G (12-371B, Millipore, USA). DNA fragments in immunoprecipitated samples were quantified by quantitative real-time PCR with published primers designed around the putative promoter regions of $b d n f$ PI-V [22].

\section{Electrophysiology}

Mice were deeply anesthetized with $40 \mathrm{mg} \mathrm{kg}^{-1}$ pentobarbital, and the brains were immediately removed and immersed in ice-cold oxygenated artificial cerebrospinal fluid (ACSF; $2.0 \mathrm{mM} \mathrm{KCl,} 125 \mathrm{mM} \mathrm{NaCl}, 1.2 \mathrm{mM}$

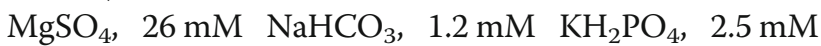
$\mathrm{CaCl}_{2}$ and $11 \mathrm{mM}$ glucose). Parasagittal sections $(300 \mu \mathrm{m})$ were cut using a vibrating microtome (Leica VT1000S, Leica Biosystems) at $4-5^{\circ} \mathrm{C}$ in ACSF, and the sections were pre-incubated in oxygenated ACSF at $30^{\circ} \mathrm{C}$ for at least $1 \mathrm{~h}$. Then, one section was placed in a chamber with an $8 \times 8$ microelectrode array (Alpha MED Sciences,
Panasonic) and kept submerged in artificial cerebrospinal fluid (aCSF; $1-2 \mathrm{ml} \mathrm{min}^{-1}$ ), The ACSF temperature in the recording chamber was maintained at $34^{\circ} \mathrm{C}$ by a heat exchanger. The MED64 system (Alpha MED Sciences, Panasonic, Japan) was used to record the fEPSPs in CA1 neurons by stimulating the Schaeffer fibers from CA3. LTP was induced by applying three trains of high-frequency stimulation (HFS; $100 \mathrm{~Hz}, 1$-s duration) separated by $20 \mathrm{~s}$.

\section{HAT and HDAC activity assays}

The activity of HAT was assayed using a HAT activity assay kit (p-4003, Epigentek, NY, USA), and the activity of HDACs was assayed using a HDAC activity assay kit (P-4034, Epigentek, USA), following the manufacturer's instructions.

\section{Sandwich ELISA for $A \beta$}

The hippocampi of GEE and control offspring were rinsed twice in PBS and homogenized in RIPA buffer (P0013D, Beyotime Biotechnology, China) containing a protease inhibitor cocktail (P8340, Sigma, USA). RIPA samples were sonicated briefly and centrifuged at 12,000 $\mathrm{g}$ for $10 \mathrm{~min}$. The levels of $\mathrm{A} \beta 1-42$ and $A \beta 1-40$ in the supernatant $\left(1.5 \mu \mathrm{gll}^{-1}\right)$ were measured using a sandwich ELISA kit (E-EL-H0543, Elabscience, China) following the manufacturer's instructions.

\section{Golgi staining}

The mice were anesthetized as mentioned above and perfused intracardially with $300 \mathrm{ml}$ of $0.9 \%$ saline containing $0.5 \%$ sodium nitrite, followed by $300 \mathrm{ml}$ of $4 \%$ formaldehyde solution and the Golgi dye solution $(5 \%$ potassium dichromate, $4 \%$ formaldehyde, and $5 \%$ chloral hydrate) for $1 \mathrm{~h}$. After being perfused, the brains were dissected into $4 \mathrm{~mm} \times 4 \mathrm{~mm}$ sections and transferred to a vial containing Golgi dye solution for 5 days in the dark, followed by a solution containing $1 \%$ silver nitrate once a day for 3 days. Serial $50-\mu \mathrm{m}$-thick sections of the brain were obtained using a vibrating microtome (Leica, VT1000 S, Germany).

\section{Statistics}

Data are expressed as mean \pm s.e.m. and were analyzed using commercial software (GraphPad Prism, GraphPad Software, Inc., La Jolla, CA; SPSS version 21.0 for Windows, SPSS Inc., Chicago, IL, USA). Two-way ANOVA, one-way ANOVA or Student's t-test was used to determine different means among groups. The level of significance was set at $p<0.05$. 


\section{Results}

GEE preserves offspring cognitive capacity and synaptic plasticity in AD mice

To explore whether GEE could affect cognitive functions in AD offspring, we first created a GEE model (described in the Methods section). Then, the offspring were reared in the home cage for $7 \mathrm{~m}$, and learning and memory ability were measured by the Morris water maze (MWM) and contextual fear-conditioning (FC), respectively (Fig. 1a; Additional file 2: Figure S1).

During the 6-day learning test in the MWM, the GEE offspring could locate the hidden platform in the water maze much faster than the controls, and the difference was already very significant at the second day (Fig. 1b). During the memory test, the platform was removed at day 8, and the GEE offspring showed a significantly increased target duration $(p<0.05)$ and target crossings $(p<0.05)$ (Fig. 1c and $\mathrm{d}$ ), suggesting a potentiation of spatial memory. GEE did not change the offspring's motor function compared with the home cage controls (Fig. 1e). These data suggest that GEE can improve offspring's spatial learning and memory in AD transgenic mice.

In the contextual fear-conditioning test in separate sets of mice, we did not observe a significant difference between the two groups during training, but significantly increased freezing $(p<0.01)$ was identified in the GEE offspring during the memory test carried out the next day after training (Additional file 2: Figure S1), suggesting an improved contexture memory in the offspring by GEE.

To explore the mechanisms underlying the improved cognitive functions, we measured the memory-related synaptic plasticity in the offspring. By western blotting, we observed that GEE significantly increased the levels of GluN2A $(p<0.05)$, GluA1 $(p<0.01)$, GluA2 $(p$ $<0.01)$ (postsynaptic proteins) and synaptotagmin $(p$ $<0.05$ ) (presynaptic protein), without changing GluN2B, PSD93, PSD95, synaptophysin and synapsin-1 (Fig. 1f and g). Simultaneously, the spine density and number of spines were significantly increased in GEE offspring compared with the controls $(p<0.01)$ (Fig. $1 \mathrm{~h}$ and i). By ex vivo brain slice electrophysiological recordings, we found that GEE facilitated basal synaptic transmission, as shown by an increased input-output (I-O) curve with enhanced LTP in the hippocampus (Fig. $1 \mathrm{j}, \mathrm{k}$ and $\mathrm{l}$ ). These data suggest that the facilitated synaptic plasticity may underlie the improved memory by GEE.

\section{GEE upregulates BDNF/TrkB and histone acetylation at bdnf promoters}

BDNF is crucial for neuronal activity and synaptic functions, and a previous study has suggested that mice exposed to EE show increased BDNF expression [23].
Therefore, we measured whether BDNF upregulation was also involved in GEE offspring. We found that both protein and mRNA levels of BDNF were significantly increased in the GEE offspring $(p<0.01)$ (Fig. 2a-d) with increased phosphorylation of $\operatorname{TrkB}$ at tyrosine-816 $(p$ $<0.05$ ) (Fig. 2e-g), indicating that activation of BDNF signaling may underlie the increased expression of synaptic proteins by GEE.

To explore the mechanisms underlying the augmented BDNF expression, we first analyzed the mRNA level of $b d n f$ variants in 7-m-old offspring hippocampus. We found that five $b d n f$ transcripts (I-V) were significantly increased in the GEE offspring ( $p<0.01)$ (Fig. $2 \mathrm{~h}$ and i). To further explore the mechanism by which the corresponding promoters might be regulated by GEE to lead to the increased $b d n f$ expression, we measured histone acetylation at 5 different $b d n f$ promoter-binding regions using chromatin immunoprecipitation (ChIP). The results showed that GEE increased histone (H4) acetylation at bdnf $\mathrm{P} 1, \mathrm{P} 3, \mathrm{P} 4$ and $\mathrm{P} 5$, and $\mathrm{H} 3$ acetylation at $b d n f$ P1 and P2 (Fig. 2j and k). These data suggest that GEE may stimulate BDNF expression by enhancing histone acetylation at its specific promoter-binding regions.

\section{GEE promotes histone acetylation and BDNF expression by activating HAT in offspring}

To investigate upstream factors of the enhanced acetylation at $b d n f$ promoter regions, we measured the activities of HAT and HDACs in the offspring embryos and the adult hippocampus. First, we confirmed that GEE significantly increased levels of total acetylated $\mathrm{H} 3(p$ $<0.01$ ) and H4 $(p<0.01)$ (H3ac and H4ac) and K14and K12-acetylation of H3 $(p<0.01)$ and H4 $(p<0.05)$ (H3K14ac, H4K12ac) in E19 embryonic brains (Fig. 3a and b) and 7-m-offspring hippocampus (Fig. 3d and e), respectively. The increases in $\mathrm{H} 3 \mathrm{ac}$ and $\mathrm{H} 4 \mathrm{ac}$ were also detected by immunofluorescence staining in 7-m-offspring hippocampus with GEE exposure (Additional file 3: Figure S2). Simultaneously, BDNF expression was upregulated, while the total protein levels of $\mathrm{H} 3$ and H4 were not changed (Fig. 3a, b, d and e). By activity assay and western blotting analyses, we found that GEE significantly upregulated HAT activity without changing the expression and activity of HDACs (Fig. $3 c-f)$. These data together indicate that GEE may potentiate the expression of neurotrophic proteins (such as BDNF) via activating HAT-mediated histone acetylation during embryonic development, thus improving memory in the adult offspring.

To validate the critical role of the embryonic activation of HAT in GEE-induced histone acetylation and activation of BDNF/TrkB signaling, we intraperitoneally injected HAT inhibitor (C646 $5 \mathrm{mg} \mathrm{kg}^{-1}$ ) into the pregnant mice starting at day 5 after exposure to EE. We 


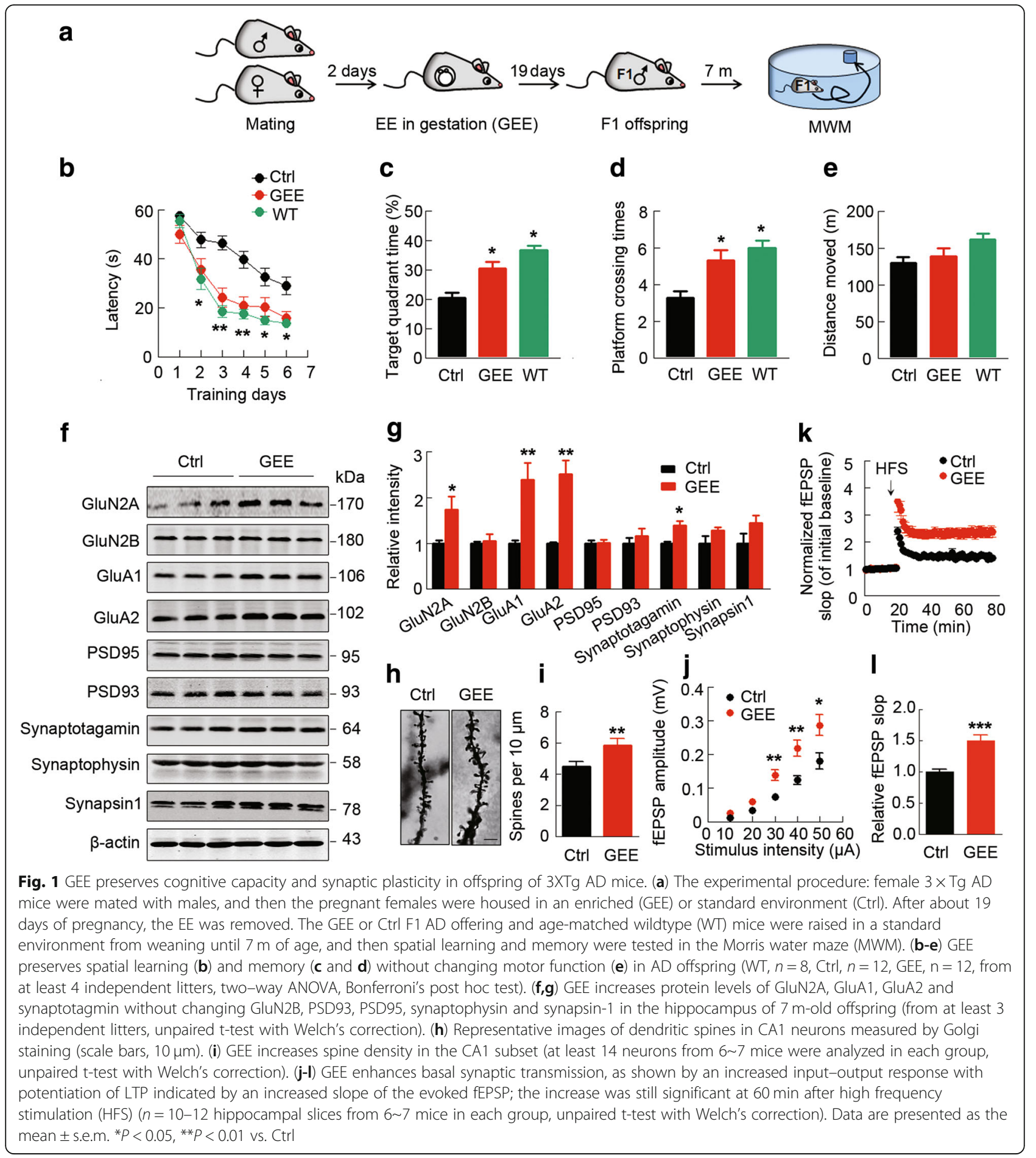

confirmed that the activity of HAT and the levels of histone acetylation and BDNF expression were all increased with the upregulation of BDNF in E19 embryonic brains after GEE exposure, while simultaneous inhibition of HAT to roughly normal levels abolished the GEE-induced histone acetylation and BDNF upregulation (Fig. 3g-i). Injection of C646 did not change the weight of the embryos (Additional file 4: Figure S3). These data confirm the role of HAT activation in GEE-induced histone acetylation and BDNF expression in the offspring.

Furthermore, by correlation analysis, we observed a positive association between GEE-improved spatial memory and HAT activity (Additional file 5: Figure S4a, 


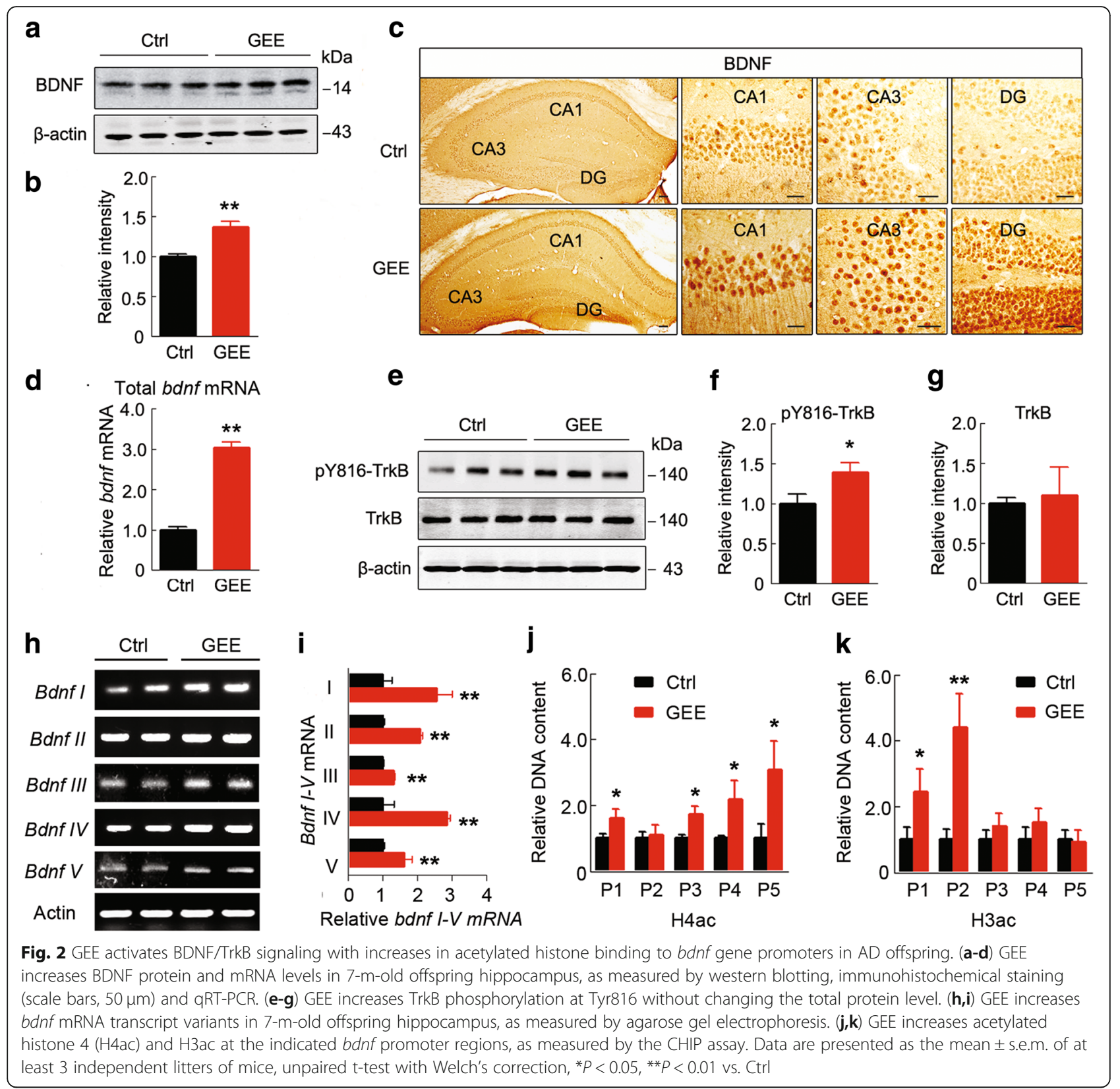

b and c). In contrast, no correlation was detected between hippocampal HDACs and spatial performance after GEE treatment (Additional file 5: Figure S4d, e and f). These data further support the critical role of HAT activation in the GEE-induced memory improvement.

\section{GEE activates HAT by upregulating CaMKIV and ERK in offspring}

Previous studies have suggested that CaMKIV and ERK can activate HAT $[24,25]$. Therefore, we measured the expression and activity-associated phosphorylation of the kinases in cytoplasmic and nuclear fractions. We found that both total $(p<0.05)$ and phosphorylated levels of CaMKIV $(p<0.01)$ were significantly increased in the nuclear fractions of the E19 offspring brain after GEE exposure in which p-CaMKIV was exclusively detected in the nuclear fraction (Fig. 4a and b). p-ERK was also significantly increased $(p<0.01)$ in the cytoplasmic fraction, while total ERK was not changed in either the nuclear or cytoplasmic faction after GEE (Fig. 4a-c). In addition, we measured the expression of $\mathrm{CK} 2 \alpha$, the upstream kinase of HDACs, but no change was found (Fig. 4a-c). By co-immunoprecipitation, we found that GEE increased the association of CaMKIV with CREB-binding protein (CBP), an important subtype of HAT (Fig. 4d) with enhanced CBP phosphorylation 

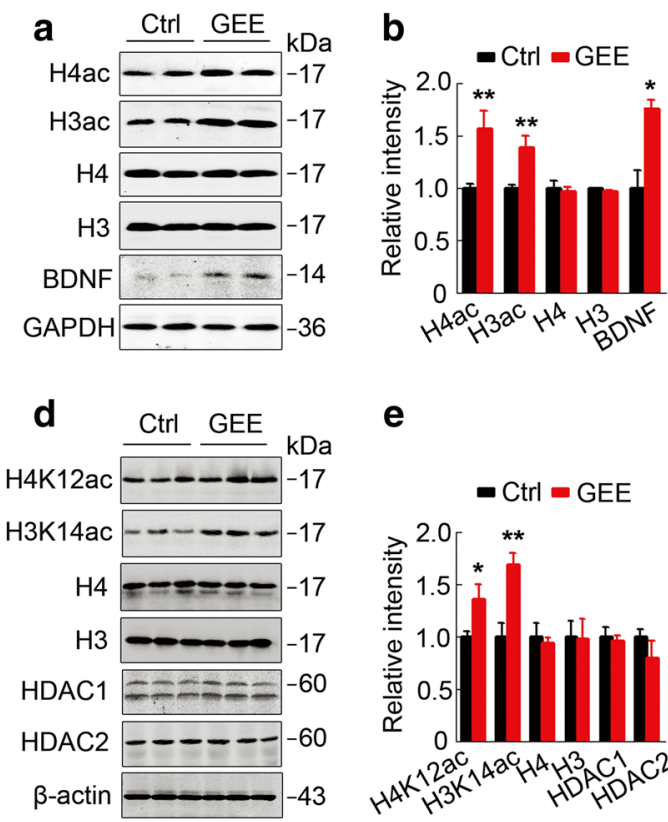

e

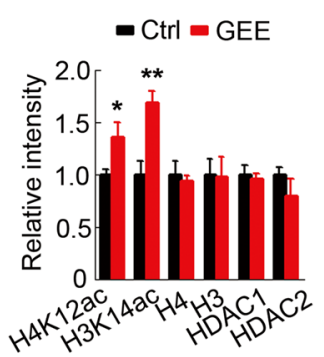

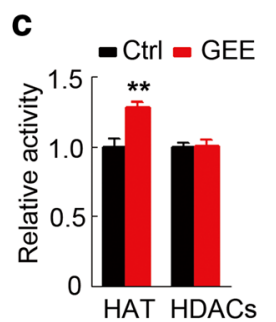

$\mathbf{f}$

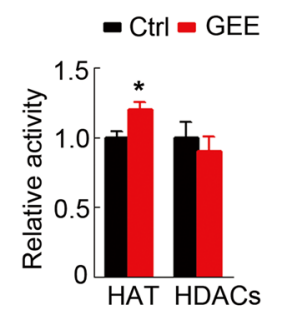

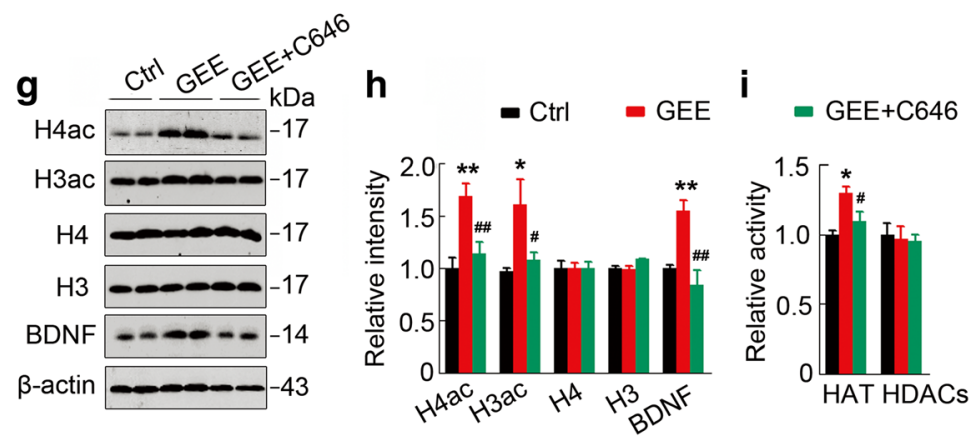

Fig. 3 HAT activation mediates GEE-potentiated histone acetylation and BDNF expression in AD offspring. (a,b) GEE increases acetylation of histone $4(\mathrm{H} 4 \mathrm{ac})$ and histone $3(\mathrm{H} 3 \mathrm{ac})$ without changing the total levels of $\mathrm{H} 4$ and $\mathrm{H} 3$ in the embryo (E19), as measured by western blotting $(n=$ 3, unpaired t-test). (d,e) GEE increases H4 acetylation at K12 (H4K12ac) and H3 at K14 (H3K14ac) in 7-m-old offspring hippocampus without changing the total levels of $\mathrm{H} 4$ and $\mathrm{H3}$ ( $n=3$, unpaired t-test). (c,f) GEE activates histone acetyltransferase (HAT) without changing histone deacetylases (HDACs) in embryos (Ctrl, $n=6, \mathrm{GEE}, \mathrm{n}=8$, unpaired t-test) and 7-m-old offspring hippocampus ( $n=9$ per group, unpaired t-test). (gi) Simultaneous inhibition of HAT by intraperitoneal injection of C646 during pregnancy abolishes GEE-induced $\mathrm{H} 4$ and $\mathrm{H} 3$ acetylation and as well as BDNF upregulation ( $n=4 \sim 6$, one-way ANOVA). Data are presented as the mean \pm s.e.m. of at least 3 independent litters of mice. ${ }^{*} P<0.05,{ }^{* *} P$ $<0.01$ vs. Ctrl; ${ }^{\#} P<0.05,{ }^{\# \#} P<0.01$ vs. GEE

(Fig. 4e). These data indicate that the upregulation of CaMKIV and ERK can be upstream of the GEE-induced HAT activation.

\section{Upregulation of IGF1/IGF1R controls GEE-potentiated CaMKIV/ERK-HAT-BDNF signaling}

A previous study has shown that retinal IGF1R is activated in normal mice subjected to EE [26]. Here we found that GEE significantly activated IGF1R with an upregulation of CaMKIV/ERK/HAT/BDNF signaling in the offspring of $\mathrm{AD}$ mice, while simultaneous inhibition of IGF1R by intraperitoneal injection of BMS-536924 (BMS) abolished the GEE-induced upregulation of CaMKIV and ERK activity, histone acetylation and BDNF expression (Fig. 5a,b). Furthermore, brain lateral ventricular infusion of IGF1 mimicked the GEE effects, i.e., activation of IGF1R with upregulation of CaMKIV/ERK and histone acetylation; while simultaneous inhibition of IGF1R by BMS attenuated the IGF1 effects in naïve mice (3 m old) (Fig. 5c,d). In HEK293 cells, upregulation of IGF1R by addition of IGF1 to the culture medium (100 $\mathrm{ng} / \mu \mathrm{l})$ activated CaMKIV and ERK with increased histone acetylation, while inhibition of IGF1R by picropodophyllin (PPP, $1 \mu \mathrm{mol} / \mathrm{L}$ ) or BMS-536924 (BMS, 100 $\mathrm{nmol} / \mathrm{L}$ ) attenuated CaMKIV and ERK activation (Fig. $5 \mathrm{e}, \mathrm{f})$. Furthermore, simultaneous inhibition of ERK or CaMKIV by GDC0994 (GDC, $6 \mathrm{nmol} / \mathrm{L}$ ) or expression of the CaMKIV-K75E [20] (a dominant negative mutant 

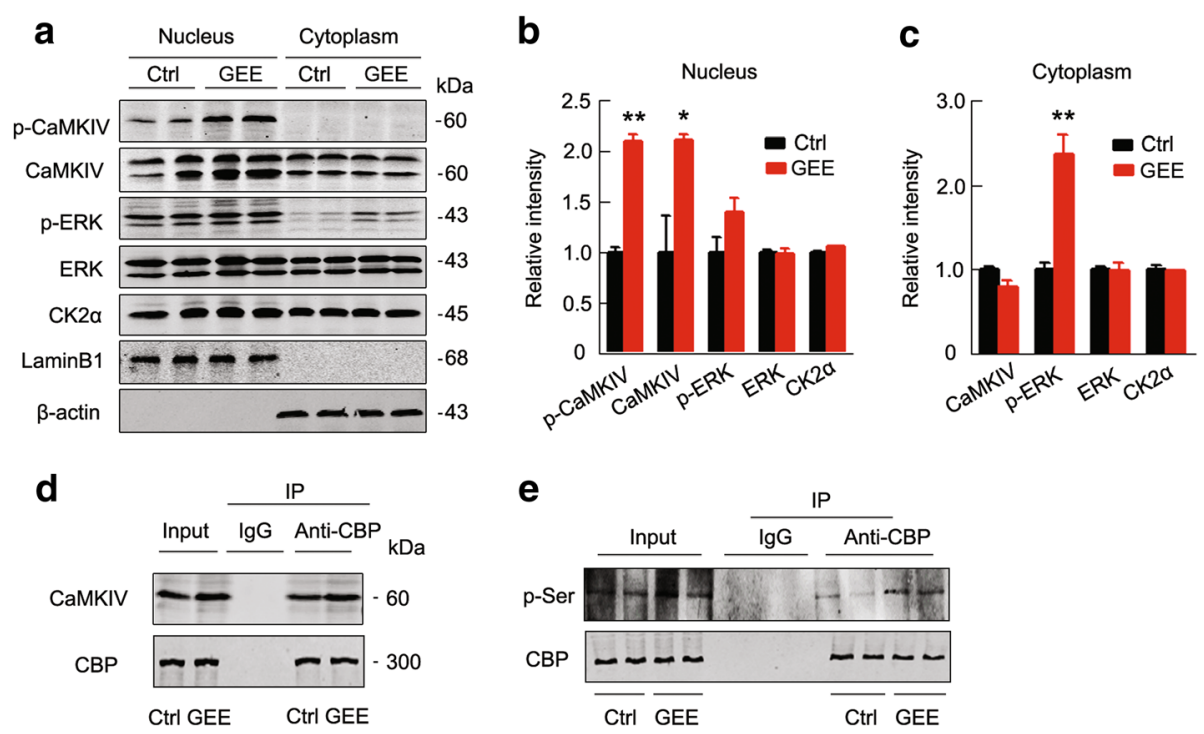

Fig. 4 GEE upregulates CaMKIV and ERK and increases CaMKIV-CBP binding in the E19 AD embryo. (a-c) GEE increases total and the phosphorylated CaMKIV in the nuclear fraction of E19 embryo brain, as measured by western blotting. (d) GEE increases the association of CaMKIV with CREB-binding protein (CBP), as measured by Co-immunoprecipitation. (e) GEE increases CBP phosphorylation, as measured by immunoprecipitation using anti-CBP and western blotting using anti-pSer antibody. Data are presented as the mean \pm s.e.m. of at least 3 independent litters of mice, unpaired t-test, ${ }^{*} P<0.05,{ }^{* *} P<0.01$ vs. Ctrl

of CaMKIV) to block the function of endogenous CaMKIV abolished IGF1-induced histone acetylation and CaMKIV/ERK activation (Fig. 5g,h). GEE also increased host (mother) plasma IGF1 levels with an increase in IGF1 in E19 embryo brain (Fig. 5i,j). Taken together, these data suggest that the upregulation of IGF1/IGF1R controls CaMKIV/ERK-HAT-BDNF signaling during GEE.

\section{CaMKIV phosphorylation at Tyr136/172 is essential for IGF1R-promoted histone acetylation}

IGF1R may induce CaMKIV phosphorylation through AMPAR-dependent L-type calcium channels in adult neurons [27]. In HEK293 cells that barely express endogenous AMPAR, we also detected the regulation of IGF1R on CaMKIV, suggesting the involvement of other mechanisms. To test this hypothesis, we performed a co-immunoprecipitation. We observed an association of IGF1R with CaMKIV, and GEE enhanced the association in E19 embryos (Fig. 6a, b). Furthermore, we detected hyperphosphorylated CaMKIV at tyrosine residues after GEE, which could be reversed by IGF1R inhibition (Fig. 6c, d). To predict the phosphorylation site(s) of CaMKIV, we used the NetPh3.1 Server software and found that Y136 and Y172 could be phosphorylated by IGF1R. For this analysis, we expressed site-specifically mutated CaMKIV plasmids (EGFP-CaMKIV-Y136F or EGFP-CaMKIV-Y172F or EGFP-CaMKIV-Y136F/Y172F) in HEK293 cells for $24 \mathrm{~h}$ and then treated the cells with IGF1 (100 ng/ $\mu \mathrm{l})$ for $2 \mathrm{~h}$. We observed that mutation of CaMKIV at Y136/Y172 dose-dependently blocked IGF1-induced CaMKIV phosphorylation with reduced histone acetylation (Fig. 6e-g). Immunofluorescence data showed that IGF1 induced nuclear translocation of CaMKIV, while mutation of at Tyr172 abolished IGF1-induced nuclear translocation of CaMKIV (Fig. 6h). These data suggest that IGF1R may phosphorylate/activate CaMKIV to stimulate histone acetylation.

\section{GEE reduces $A \beta$ and tau pathologies in adult offspring hippocampus}

The $3 \times \mathrm{Tg} \mathrm{AD}$ mice showed significant $\mathrm{A} \beta$ and tau pathologies. We observed that GEE exposure significantly attenuated tau hyperphosphorylation at multiple $\mathrm{AD}$-associated sites in the hippocampus, as measured by western blotting and immunohistochemical staining (Fig. 7a-c, Additional file 6: Figure S5). GEE exposure also decreased the A $\beta 1-40$ level $(p<0.05)$, with significantly reduced $\mathrm{A} \beta$ plaques in 10 -m-old offspring cortex and hippocampus (Fig. $7 \mathrm{~d}$ and e). GEE activated AKT with inhibition of the downstream GSK-3 $\beta(p<0.05)$ (Fig. 7f and g), which not only partially explained the mechanisms underlying the attenuated tau phosphorylation but also indicated an activation of cell survival signaling [28]. These data together suggest that GEE may improve brain metabolism to arrest the dominant gene mutation-induced pathologies in the offspring, which can contribute to the improved synaptic plasticity and memory capacity. 

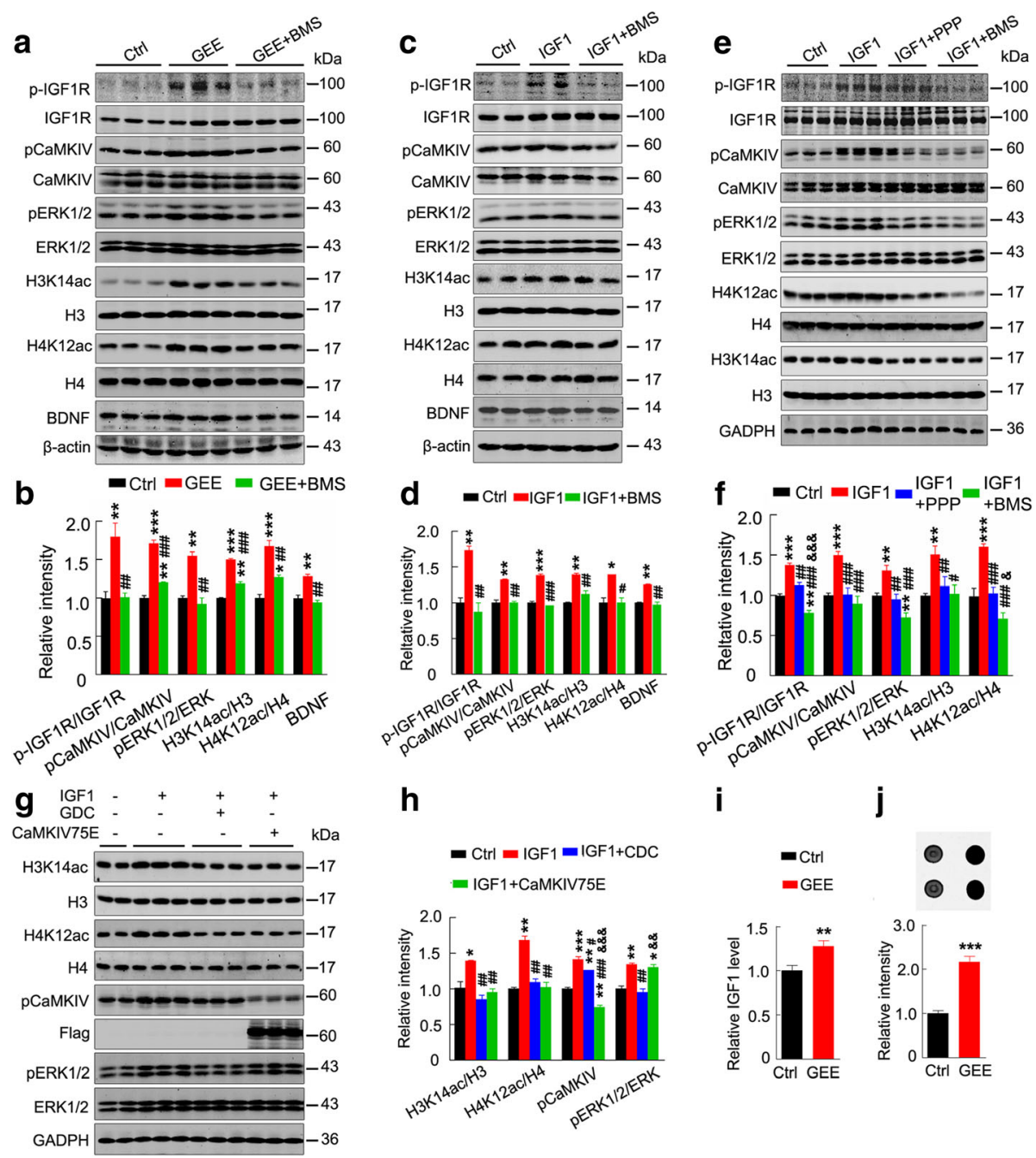

h i

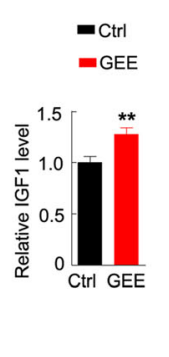

j

- Ctrl $=$ IGF1 $=$ IGF1+CDC

- IGF1+CaMKIV75E

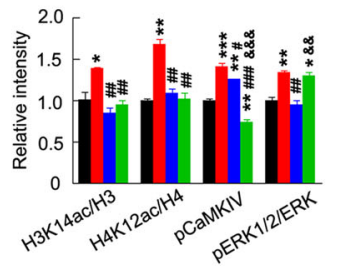

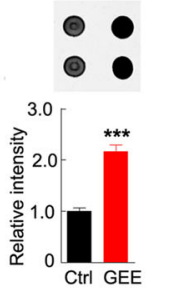

Fig. 5 GEE activates IGF1R-CaMKIV/ERK signaling and thus promotes histone acetylation and BDNF expression. (a,b) In 3XTg AD mice, GEE activates IGF1R with upregulation of CaMKIV/ERK/HAT/BDNF signaling in their offspring (7 m old), while simultaneous inhibition of IGF1R by BMS abolishes GEE-induced histone acetylation, CaMKIV and ERK activation, and BDNF expression ( $n=3$, one-way ANOVA, ${ }^{*} P<0.05,{ }^{* *} P<0.01,{ }^{* * *} P<$

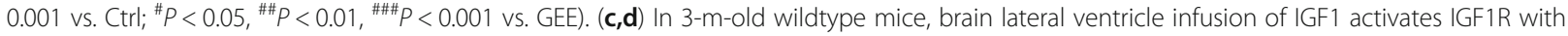
an upregulation of CaMKIV/ERK/HAT/BDNF signaling, while simultaneous inhibition of IGF1R by BMS attenuates these effects $(n=3$, one-way

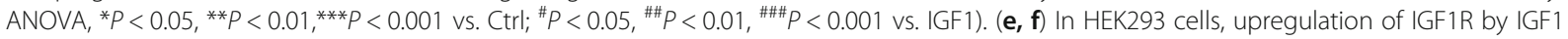
treatment activates CaMKIV and ERK with increased histone acetylation, while inhibition of IGF1R by PPP or BMS attenuates these effects $(n=6$,

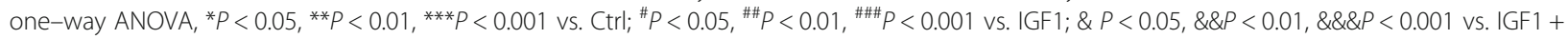
PPP). (g, h) In HEK293 cells, simultaneous inhibition of ERK or CaMKIV by CDC0994 or by expressing the inactive CaMKIVK75E abolishes IGF1induced histone acetylation ( $\mathrm{n}=3$, one-way ANOVA, ${ }^{*} P<0.05$, ${ }^{*} P<0.01,{ }^{* * *} P<0.001 \mathrm{vs}$. Ctrl; ${ }^{\#} P<0.05,{ }^{\# \#} P<0.01$, ${ }^{\# \#} P<0.001$ vs. IGF1; \& $P<0.05$, $\& \& P<0.01, \& \& \& P<0.001$ vs. IGF1 + CDC0994). (i) GEE increases the plasma level of IGF1 in the pregnant host, as measured by ELISA ( $n=8$, unpaired t-test, ${ }^{* *} P<0.01$ vs. Ctrl). (j) GEE increases the IGF1R level in E19 embryo brain, as measured by dot blotting $\left(n=5\right.$, unpaired t-test, ${ }^{* * *} P$ $<0.001$ vs. Ctrl). Data are presented as the mean \pm s.e.m. and offspring tissue collected from at least 3 independent litters of mice

\section{Discussion}

Based on current protocols in molecular biology, autosomal dominant hereditary AD genes (such as APP, PS1/ 2) are feasibly sieved out in the parental generations for diagnosis. However, to date, no effort has been made to examine this type of early diagnosis of hereditary AD. The major hindrance is due to the lack of efficient interventions, i.e., why should those very young people (carrying dominant $\mathrm{AD}$ mutant genes) be told that they or their children will suffer from early onset AD if nothing good can be done to help them?

Building the brain reserve before the onset of dementia could be a promising strategy to prevent AD. The enriched environment (EE) is a well-known type of cognitive stimulation that has been tested in many adult $\mathrm{AD}$ models. The discrepant readouts raise the possibility that decreasing brain dynamics along with ageing might limit the efficiency of EE. Thus, we shifted our focus to the 


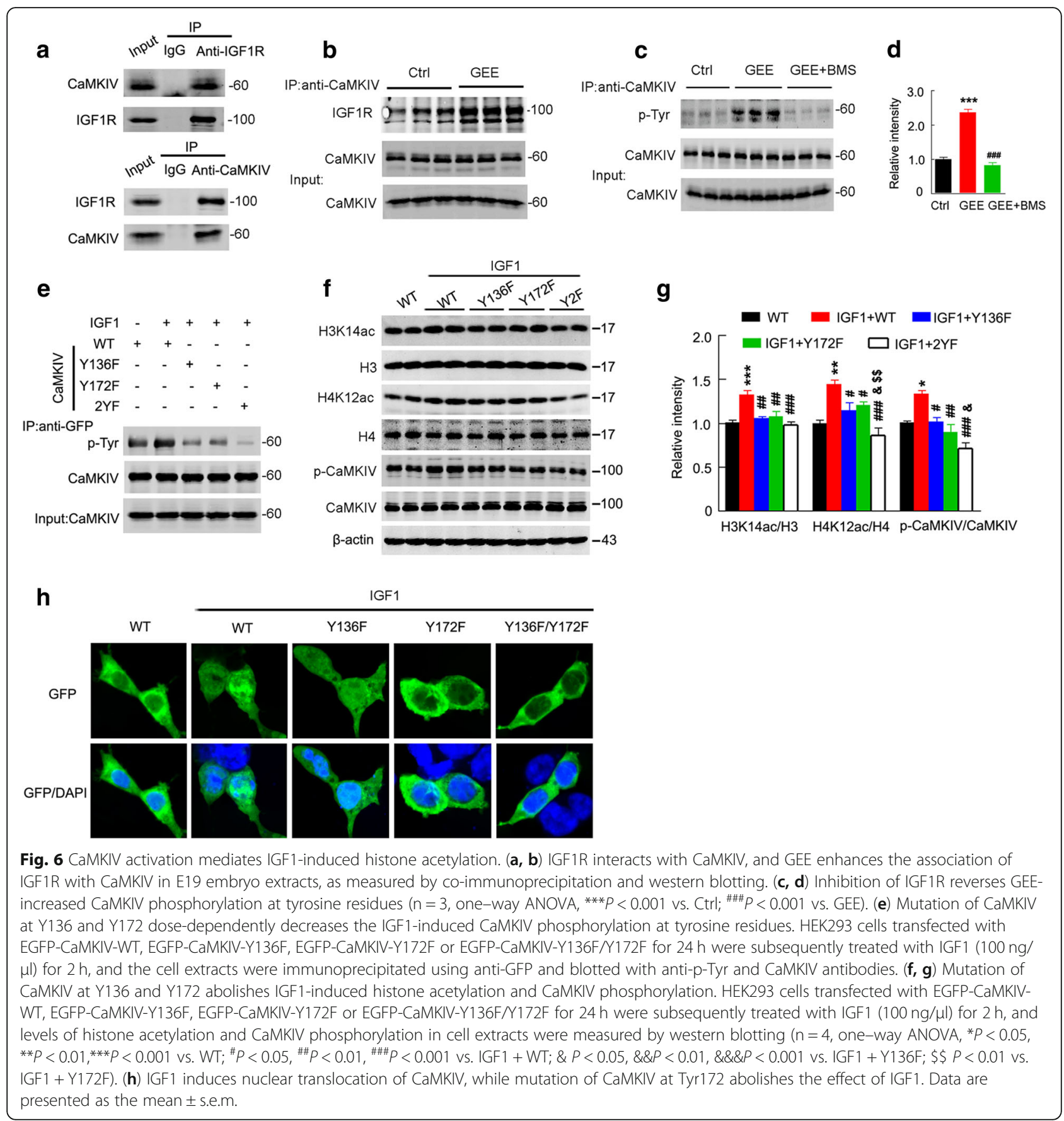

embryonic period, one of the most dynamic periods of life, and employed GEE in AD mice. We found that GEE significantly preserved synaptic plasticity and memory capacity with remarkably ameliorated pathologies in 710-m-old offspring, and the molecular mechanism involved an upregulation of IGF1/IGF1R/CaMKIV/HAT/ BDNF signaling (Fig. 8). These findings reveal that maternal GEE can arrest the offspring's pathological and behavioral progressions in the AD model. As there is currently no cure for $\mathrm{AD}$, our findings provide a feasible and promising non-drug-involved approach for intervention in hereditary $\mathrm{AD}$ at a very early stage.

Previous studies have focused on the influence of EE on individuals per se who have received EE (F0), and paradoxical findings have been obtained. Some studies have shown that EE has significant benefits in animal models of neurodegenerative diseases, including $\mathrm{AD}$ [29-32]; long-term or short-term exposure to EE can improve synaptic plasticity $[33,34]$ and thus mitigate cognitive deficits [32, 33]; EE can reduce amyloid 
a

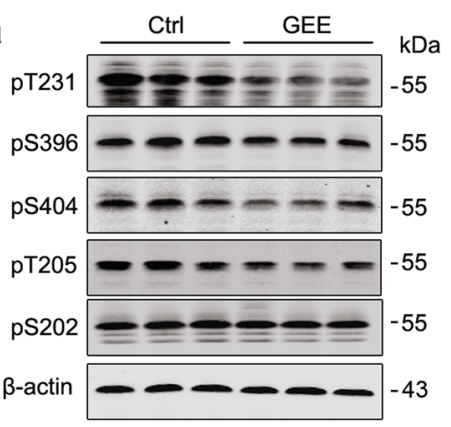

C

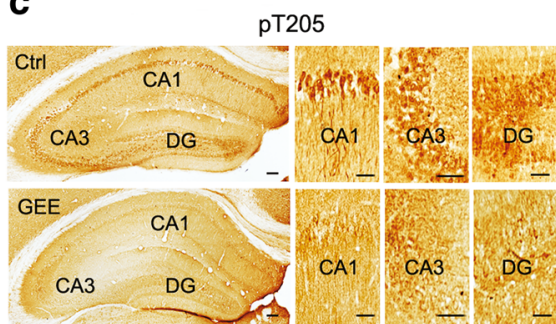

b

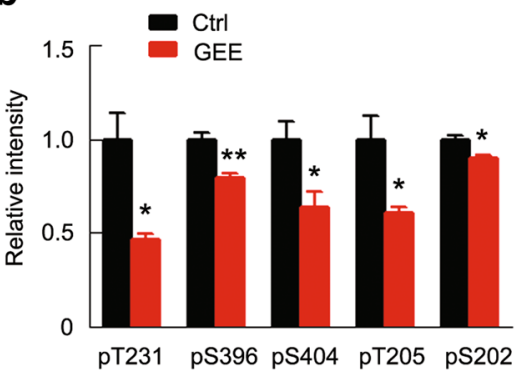

d
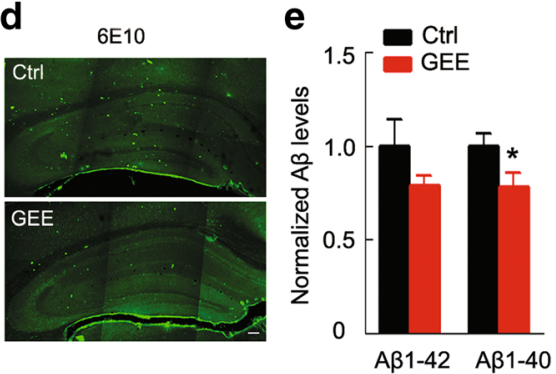

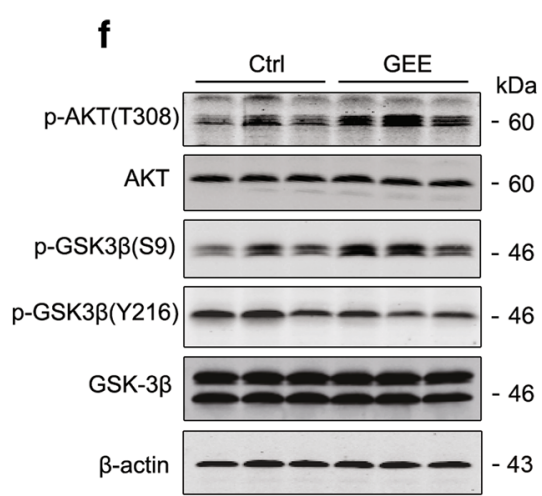

g
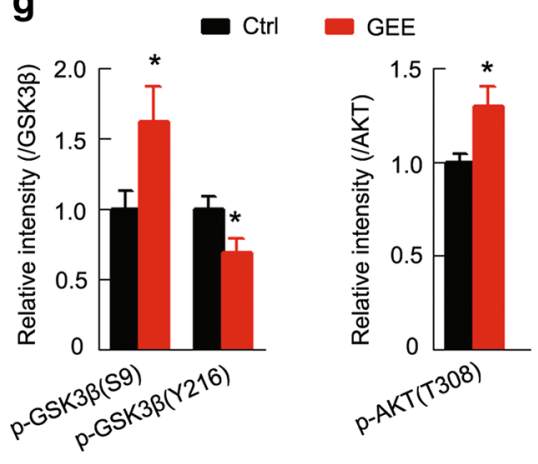

Fig. 7 GEE reduces tau and A $\beta$ pathologies in 10-m-old AD offspring hippocampus. (a-c) GEE attenuates tau hyperphosphorylation at multiple AD-associated sites, as measured by western blotting and immunohistochemical staining (scale bar, $50 \mu m$ ). (d,e) GEE decreases the A $31-40$ level with reduced $A \beta$ plaques in the cortex and hippocampus, as measured by ELISA and immunofluorescent staining (scale bars, 50 um, from at least 4 independent experiments, unpaired t-test). (f,g) GEE activates AKT, as shown by increased phosphorylation at Thr308 (pT308AKT) with inhibition of GSK-3 $\beta$ determined by increased pS9GSK-3 $\beta$ and reduced pY216GSK-3 $\beta$. The phosphorylation level of AKT and GSK-3 $\beta$ was normalized against

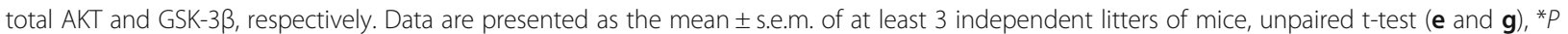
$<0.05,{ }^{*} P<0.01$ vs. Ctrl

deposition and tau hyperphosphorylation [32]. In contrast, data have also been obtained to support EE-induced plaque formation in a double transgenic mouse model of $\mathrm{AD}$ [35], or a failure of $\mathrm{EE}$ to rescue working memory deficits or neuron loss in APP/ PS1KI mice [36]. The reason for this discrepancy is currently not fully understood. We speculate that different ages may contribute to the distinct effects of $\mathrm{EE}$, in addition to the genetic variability of the $\mathrm{AD}$ animal models employed in these studies. In the present study, we observed a significant beneficial influence of GEE on AD offspring compared with age-matched controls.
The mechanism underlying the improved cognition by GEE is currently not clear. In normal rats, offspring from maternal swimming or treadmill running show an enhanced short-term memory with significantly increased $b d n f$ mRNA in the hippocampus [8, 10, 37]. Maternal voluntary exercise during pregnancy promotes BDNF expression in male offspring with enhanced learning, while simultaneous inhibition of BDNF action (TrkB inhibitor) abolishes the effects of maternal exercises on memory retrieval [11]. Maternal enrichment accelerates fetal retinal development with an increase in IGF, which can be inherited by the offspring from the mother [6]. These data strongly suggest that the upregulation of 


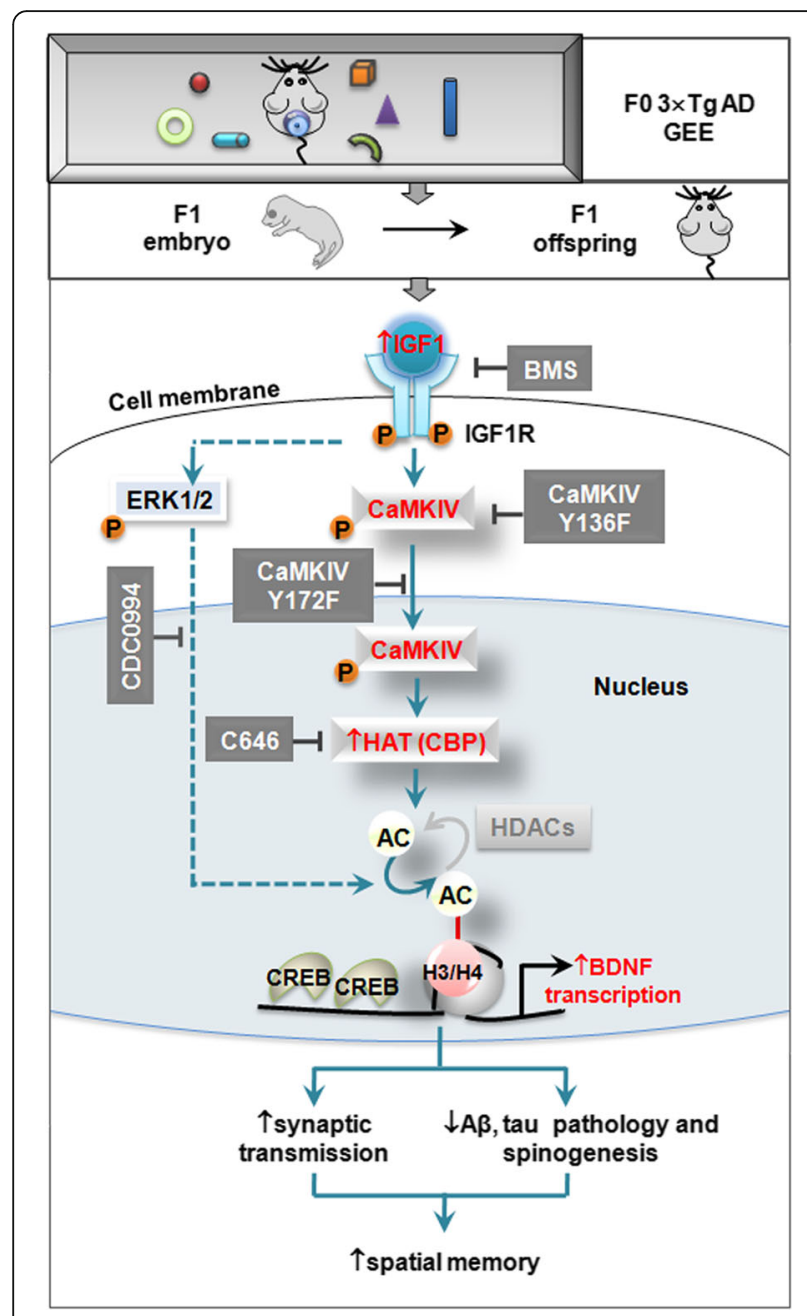

Fig. 8 Proposed working model. Gestational environment enrichment (GEE) in mothers (F0) upregulates IGF1/IGF1R in offspring (F1, embryo and the adults), which in turn phosphorylates/ activates ERK and CaMKIV. The phosphorylated pY172-CaMKIV is translocated to the nuclear fraction where it phosphorylates HAT (CBP), thus inducing hyperacetylation at bdnf promoters and upregulating BDNF expression. BDNF preserves synaptic plasticity and improves AD pathologies, which eventually leads to an improved spatial memory capacity. Blockade of HAT, CaMKIV, ERK, and IGF1R abolishes the beneficial effects of GEE

neurotrophic factors and altered neural development are involved in exercise-induced cognitive improvement. The BDNF level has been found to be decreased in the brain of $A D$ postmortem samples and $A D$ animal models [38-41], and defective BDNF is involved in the synaptic dysfunction and cognitive impairment in $\mathrm{AD}$ [39, 41-43], while the upregulation of the BDNF pathway can reverse these phenomena [44-48]. In the present study, we also observed an upregulation of BDNF signaling in AD offspring after GEE. Although decreased BDNF levels are well recognized in the brain of $\mathrm{AD}$ patients and in animal models [38-41], at present, no medicine targeting BDNF or its receptor, TrkB, has been clinically shown to exert precise anti-AD effects, which may be due to difficulties related to entry of the drugs into the brain and their short half-life. Thus, the search for a continuous and effective strategy to elevate brain BDNF or activate its signal is of great significance for the treatment of AD. BDNF expression is regulated epigenetically, for example, by DNA methylation and histone acetylation [49]. The offspring from both maternal and parental EE showed a global decrease in DNA methylation in the hippocampus and frontal cortex with an increase in exploratory behavior in the open field test [50]. Histone acetylation is a key mechanism in regulating $b d n f$ transcription $[51,52]$, and increases in histone acetylation enhance BDNF mRNA expression [53, 54]. Here we found that GEE increased histone acetylation at multiple $b d n f$ promoter regions, which was accompanied by global histone hyperacetylation both in the embryo and the offspring hippocampus, and the inhibition of HAT abolished GEE-enhanced BDNF expression. GEE specifically activates CaMKIV, a crucial kinase for HAT activation, without altering HDACs or the upstream CK2 $\alpha$. These data suggest that GEE can induce the embryo-adult elevation of BDNF via histone hyperacetylation and upregulation of $b d n f$ transcription by activating CaMKIV-HAT signaling.

One of the important novel findings of the present study is that GEE-upregulated IGF1, as a key contributor, drove the activation of CaMKIV-HAT signaling. We systemically demonstrated that GEE activated the CaMKIV/ERK/HAT/BDNF signaling pathway by upregulating IGF1/IGF1R. GEE enhanced the association of IGF1R with CaMKIV and, thus, increased CaMKIV phosphorylation and its nuclear translocation by IGF1R. The activation of retinal IGF1R in normal mice who received EE exposure has been reported [26], but our current data demonstrated that GEE could upregulate the IGF1/ IGF1R signaling pathway in AD offspring. We also revealed a site-specific phosphorylation of CaMKIV by IGF1R, thus providing a novel mechanism by which IGF1R can induce CaMKIV phosphorylation through AMPAR-dependent L-type calcium channels [27].

BDNF activates a variety of signaling cascades, including PI3K/Akt [55], and activation of BDNF/TrkB promotes neuronal survival and synaptic plasticity largely through Akt [56-58]. Increasing evidence suggests that the PI3K/Akt pathway is inhibited in the AD brain [59] or by $A \beta$ exposure $[60,61]$. GSK- $3 \beta$ is downstream of Akt [62] , which is responsible for AD-like tau hyperphosphorylation [63]. We found that GEE activated $\mathrm{BDNF} /$ TrkB signaling in AD offspring, which can inhibit GSK-3 $\beta$ by activating Akt and thus attenuate tau hyperphosphorylation. Previous studies have shown that $\mathrm{BDNF}$ can reduce the $\mathrm{A} \beta$ level in $\mathrm{AD}$ transgenic mice 
$[64,65]$, and here we found that GEE could decrease the level of $A \beta$ in $A D$ offspring.

Aerobic exercise training increases the hippocampus/ brain volume and improves cognitive function in aging humans [66-68]. Randomized clinical trials with longitudinal follow-up studies have also shown that physical activity can improve cognitive function in older adults at risk for $\mathrm{AD}$ or prevent the onset of dementia [69, 70]. The human studies have also indicated that maternal physical and/or cognitive exercise is not only beneficial for the amniotic fluid, placental viability and body fat deposition, but it also affects neurodevelopment in the offspring [71-73]. High levels of leisure-time physical activity (e.g., jogging, aerobics, yoga, weight-lifting) during pregnancy are associated with increased vocabulary in offspring [74]. Exercise increases the plasma levels of IGF1 and BDNF with maternal hormonal changes in pregnancy [75]. The level of IGFBP-2, an inhibitory factor of IGF, is increased [76, 77], while insulin and IGF1 responsiveness are reduced in the $\mathrm{AD}$ patients [78]. Studies also show that a decrease in the plasma IGF1 level can predict cognitive decline in $\mathrm{AD}$ [79], and the elevation of IGF1 mediates the environment enrichmentand exercise-induced beneficial effects on the central nervous system [80-83]. The enriched environments used in the current study included the running wheel, toys and gregarious living, which mimic increased exercise, an enriched living environment, and an enhanced social interaction. These environmental enrichments, together with the measurement of plasma IGF1, may be applied for human studies in the future.

In the progression of $\mathrm{AD}$ neurodegeneration, compensation involves the previously acquired functional reserve, while building this reserve relies on cognitive stimulation before the onset of disease [84]. The protocol used in the present study consisted of the idea that individuals who continually receive intellectually stimulating activities maintain higher and prolonged intellectual abilities [85, 86], and those with good physical fitness show improved memory in old age. More interestingly, compared with the uncertain benefits of EE in adults, GEE in our study could produce embryo-adult benefits via the IGF1R/CaMKIV/HAT/BDNF pathway to prevent $A D$, which may be a promising method for $A D$ prevention.

\section{Conclusions}

In summary, this is the first report to show that GEE efficiently delays $\mathrm{AD}$ progression via inducing a sustained stimulation of the IGF1R/CaMKIV/HAT/BDNF pathway, which not only provides a promising strategy for early intervention of AD but also reveals novel molecular mechanisms for the lasting enhanced brain plasticity induced by GEE.

\section{Additional files}

\begin{abstract}
Additional file 1: Table S1. Antibodies employed in this study. (DOCX $206 \mathrm{~kb}$ )

Additional file 2: Figure S1. GEE improves spatial memory in offspring, as measured by contextual fear-conditioning. GEE was conducted as shown in Fig. 1a. (a) F1 offspring were raised in a standard environment from weaning until $7 \mathrm{~m}$ of age when memory was tested using contextual fear conditioning (FC). (b) GEE improved memory without changing learning ability in the offspring. Ctrl, $n=16, \mathrm{GEE}, n=11$, unpaired t test with Welch's correction. ${ }^{* *} P<0.01$ versus $C$ trl. Data are presented as the mean \pm s.e.m. (DOCX $113 \mathrm{~kb})$
\end{abstract}

Additional file 3: Figure S2. GEE increases $\mathrm{H} 3$ and $\mathrm{H} 4$ acetylation in the offspring hippocampus. Representative immunofluorescence images stained using acetylated $\mathrm{H}_{3}(\mathrm{H} 3 \mathrm{ac})$ and $\mathrm{H}_{4}(\mathrm{H} 4 \mathrm{ac})$ in 7-m-old offspring hippocampal subsets (CA1, CA3 and DG). Scale bars, 50 m. (DOCX 522 $\mathrm{kb})$

Additional file 4: Figure S3. Inhibition of HAT during GEE exposure has no effect on embryo weight. Embryos were weighed at E19 after GEE exposure with or without C646 treatment (HAT inhibitor). No differences in embryo weights were detected among the groups. $n=8-15$ per group, one-way ANOVA, Tukey's multiple comparisons test. Data are presented as the mean \pm s.e.m. (DOCX $32 \mathrm{~kb}$ )

Additional file 5: Figure S4. Hippocampal HAT but not HDAC activity is positively correlated with spatial memory performance after GEE treatment. (a-c) Pearson analyses show the positive correlation of HAT activity with time spent in the target quadrant and platform crossings in the MWM test, and the freezing time in FC (for original data, see Fig. 1 and Figure S1). (d-e) No correlation was detected between hippocampal HDAC activity and partial memory performance after GEE treatment. Data are presented as the mean \pm s.e.m. (DOCX $183 \mathrm{~kb}$ )

Additional file 6: Figure S5. GEE decreases tau phosphorylation in offspring hippocampus. Representative immunohistochemical images of phosphorylated tau at Ser396 and Thr231 in hippocampal subsets (CA1, CA3 and DG). Scale bars, $50 \mu \mathrm{m}$. (DOCX $2457 \mathrm{~kb}$ )

\section{Abbreviations}

AD: Alzheimer's disease; A $\beta$ : Amyloid $\beta$; BDNF: Brain derived neurotrophic factor; CaMKIV: $\mathrm{Ca}^{2+} /$ calmodulin-dependent kinase IV; CBP: CREB-binding protein; ChIP: Chromatin immunoprecipitation; FC: Contextual fearconditioning; GEE: Gestational environment enrichment; HAT: Histone acetyltransferase; IGF1: Insulin-like growth factor 1; IGF1R: Insulin-like growth factor 1 receptor; I-O curve: Input-output curve; MWM: Morris water maze; SDS-PAGE: SDS-polyacrylamide gel electrophoresis; US: Unconditioned stimulus

\section{Funding}

This work was supported in part by grants from the NSFC (91632305, 91632111, 31730035 and 81721005) and by the Ministry of Science and Technology of China (2016YFC1305800).

Availability of data and materials

The datasets used and analyzed during the current study are available from the corresponding author on reasonable request.

\section{Authors' contributions}

This study was initiated and designed by JZW; QZ, ML and SZ performed the animal behavior studies; EL and YW performed the brain slice electrophysiology recordings and analyzed the data; EL, QZ, AJX and $\mathrm{HH}$ performed the western blotting and ChIP assays; EL and QZ performed the HAT and HDAC activity assays; QZ performed the immunohistochemistry; DS, $B L, Z L$. and $X L$ performed the genotyping and analyzed the imaging data; $Y$ W, XY, QW, DK and XW helped to collect the data; $Y Y$ and J. Z W analyzed the data and interpreted the results; J Z W wrote the manuscript. All authors read and approved the final manuscript. 


\section{Ethics approval and consent to participate}

All animal research was approved by the Ethics Committee of Tongji Medical College, Huazhong University of Science and Technology. All efforts were made to minimize the number of animals used and to minimize animal suffering.

\section{Consent for publication}

Not applicable.

\section{Competing interests}

The authors declare that they have no competing interests.

\section{Author details}

'Department of Pathophysiology, School of Basic Medicine and the Collaborative Innovation Center for Brain Science, Key Laboratory of Ministry of Education of China for Neurological Disorders, Tongji Medical College, Huazhong University of Science and Technology, Wuhan 430030, China. ${ }^{2}$ Co-innovation Center of Neuroregeneration, Nantong University, Nantong 226000, China. ${ }^{3}$ Key Laboratory of Modern Toxicology of Shenzhen, Shenzhen Centre for Disease Control and Prevention, 8 Longyuan Road, Shenzhen 518055, China. ${ }^{4}$ Department of Pathology, the First Affiliated Hospital of Zhengzhou University, Zhengzhou 450052, China.

\section{Received: 25 October 2018 Accepted: 15 February 2019}

\section{Published online: 05 March 2019}

\section{References}

1. Lahiri DK, Maloney B, Zawia NH. The LEARn model: an epigenetic explanation for idiopathic neurobiological diseases. Mol Psychiatry. 2009;14: 992-1003.

2. Whalley LJ, Dick FD, McNeill G. A life-course approach to the aetiology of late-onset dementias. Lancet Neurol. 2006;5:87-96.

3. Hawkes CA, Gentleman SM, Nicoll JA, Carare RO. Prenatal high-fat diet alters the cerebrovasculature and clearance of beta-amyloid in adult offspring. J Pathol. 2015;235:619-31.

4. Nizari S, Carare RO, Hawkes CA. Increased Abeta pathology in aged Tg2576 mice born to mothers fed a high fat diet. Sci Rep. 2016;6:21981.

5. Cardenas L, Garcia-Garcia F, Santiago-Roque I, Martinez AJ, Coria-Avila GA, Corona-Morales AA. Enriched environment restricted to gestation accelerates the development of sensory and motor circuits in the rat pup. Int J Dev Neurosci. 2015;41:68-73.

6. Sale A, Cenni MC, Ciucci F, Putignano E, Chierzi S, Maffei L. Maternal enrichment during pregnancy accelerates retinal development of the fetus. PLoS One. 2007:2:e1160.

7. Cymerblit-Sabba A, Lasri T, Gruper M, Aga-Mizrachi S, Zubedat S, Avital A. Prenatal enriched environment improves emotional and attentional reactivity to adulthood stress. Behav Brain Res. 2013;241:185-90.

8. Lee HH, Kim H, Lee JW, Kim YS, Yang HY, Chang HK, Lee TH, Shin MC, Lee $\mathrm{MH}$, Shin MS, et al. Maternal swimming during pregnancy enhances shortterm memory and neurogenesis in the hippocampus of rat pups. Brain and Development. 2006;28:147-54.

9. Bick-Sander A, Steiner B, Wolf SA, Babu H, Kempermann G. Running in pregnancy transiently increases postnatal hippocampal neurogenesis in the offspring. Proc Natl Acad Sci U S A. 2006;103:3852-7.

10. Kim H, Lee SH, Kim SS, Yoo JH, Kim CJ. The influence of maternal treadmill running during pregnancy on short-term memory and hippocampal cell survival in rat pups. Int J Dev Neurosci. 2007;25:243-9.

11. Akhavan M, M-GH M, Emami-Abarghoie M, Safari M, Sadighi-Moghaddam B, A Vafaei A, Rashidy-Pour A. Maternal voluntary exercise during pregnancy enhances the spatial learning acquisition but not the retention of memory in rat pups via a TrkB-mediated mechanism: the role of hippocampal BDNF expression. Iran J Basic Med Sci. 2013.

12. Kempermann G, Kuhn HG, Gage FH. More hippocampal neurons in adult mice living in an enriched environment. Nature. 1997;386:493-5.

13. Sahay A, Scobie KN, Hill AS, O'Carroll CM, Kheirbek MA, Burghardt NS, Fenton AA, Dranovsky A, Hen R. Increasing adult hippocampal neurogenesis is sufficient to improve pattern separation. Nature. 2011;472:466-70.

14. Neeper SA, Gomez-Pinilla F, Choi J, Cotman C. Exercise and brain neurotrophins. Nature. 1995;373:109.

15. Branchi I, D'Andrea I, Fiore M, Di Fausto V, Aloe L, Alleva E. Early social enrichment shapes social behavior and nerve growth factor and brain- derived neurotrophic factor levels in the adult mouse brain. Biol Psychiatry. 2006;60:690-6.

16. Baroncelli L, Scali M, Sansevero G, Olimpico F, Manno I, Costa M, Sale A. Experience affects critical period plasticity in the visual cortex through an epigenetic regulation of histone post-translational modifications. J Neurosci. 2016:36:3430-40

17. Gapp K, Soldado-Magraner S, Alvarez-Sanchez M, Bohacek J, Vernaz G, Shu $H$, Franklin TB, Wolfer D, Mansuy IM. Early life stress in fathers improves behavioural flexibility in their offspring. Nat Commun. 2014;5:5466.

18. De Jager PL, Srivastava G, Lunnon K, Burgess J, Schalkwyk LC, Yu L, Eaton ML, Keenan BT, Ernst J, McCabe C, et al. Alzheimer's disease: early alterations in brain DNA methylation at ANK1, BIN1, RHBDF2 and other loci. Nat Neurosci. 2014:17:1156-63.

19. Graff J, Rei D, Guan JS, Wang WY, Seo J, Hennig KM, Nieland TJ, Fass DM, Kao PF, Kahn M, et al. An epigenetic blockade of cognitive functions in the neurodegenerating brain. Nature. 2012;483:222-6.

20. Yin Y, Gao D, Wang Y, Wang ZH, Wang X, Ye J, Wu D, Fang L, Pi G, Yang Y, et al. Tau accumulation induces synaptic impairment and memory deficit by calcineurin-mediated inactivation of nuclear CaMKIV/CREB signaling. Proc Natl Acad Sci U S A. 2016;113:E3773-81.

21. Liu E, Xie AJ, Zhou Q, Li M, Zhang S, Li S, Wang W, Wang X, Wang Q, Wang JZ. GSK-3beta deletion in dentate gyrus excitatory neuron impairs synaptic plasticity and memory. Sci Rep. 2017;7:5781.

22. Tsankova NM, Berton O, Renthal W, Kumar A, Neve RL, Nestler EJ. Sustained hippocampal chromatin regulation in a mouse model of depression and antidepressant action. Nat Neurosci. 2006;9:519-25.

23. Burrows EL, McOmish CE, Buret LS, Van den Buuse M, Hannan AJ. Environmental enrichment ameliorates behavioral impairments modeling schizophrenia in mice lacking metabotropic glutamate receptor 5. Neuropsychopharmacology. 2015;40:1947-56.

24. Swank MW, Sweatt JD. Increased histone acetyltransferase and lysine acetyltransferase activity and biphasic activation of the ERK/RSK cascade in insular cortex during novel taste learning. J Neurosci. 2001;21:3383-91.

25. Impey S, Fong AL, Wang Y, Cardinaux JR, Fass DM, Obrietan K, Wayman GA Storm DR, Soderling TR, Goodman RH. Phosphorylation of CBP mediates transcriptional activation by neural activity and CaM kinase IV. Neuron. 2002; 34:235-44.

26. Landi S, Ciucci F, Maffei L, Berardi N, Cenni MC. Setting the pace for retinal development: environmental enrichment acts through insulin-like growth factor 1 and brain-derived neurotrophic factor. J Neurosci. 2009;29:10809-19.

27. Marshall J, Dolan BM, Garcia EP, Sathe S, Tang X, Mao Z, Blair LA. Calcium channel and NMDA receptor activities differentially regulate nuclear C/ EBPbeta levels to control neuronal survival. Neuron. 2003;39:625-39.

28. Datta SR, Brunet A, Greenberg ME. Cellular survival: a play in three Akts. Genes Dev. 1999:13:2905-27.

29. Lazarov O, Robinson J, Tang YP, Hairston IS, Korade-Mirnics Z, Lee VM, Hersh LB, Sapolsky RM, Mirnics K, Sisodia SS. Environmental enrichment reduces Abeta levels and amyloid deposition in transgenic mice. Cell. 2005:120:701-13.

30. Jankowsky JL, Melnikova T, Fadale DJ, Xu GM, Slunt HH, Gonzales V, Younkin LH, Younkin SG, Borchelt DR, Savonenko AV. Environmental enrichment mitigates cognitive deficits in a mouse model of Alzheimer's disease. J Neurosci. 2005:25:5217-24

31. Costa DA, Cracchiolo JR, Bachstetter AD, Hughes TF, Bales KR, Paul SM, Mervis RF, Arendash GW, Potter $\mathrm{H}$. Enrichment improves cognition in AD mice by amyloid-related and unrelated mechanisms. Neurobiol Aging. 2007; 28:831-44.

32. Hu YS, Xu P, Pigino G, Brady ST, Larson J, Lazarov O. Complex environment experience rescues impaired neurogenesis, enhances synaptic plasticity, and attenuates neuropathology in familial Alzheimer's disease-linked APPswe/ PS1DeltaE9 mice. FASEB J. 2010;24:1667-81.

33. Huttenrauch M, Brauss A, Kurdakova A, Borgers H, Klinker F, Liebetanz D, Salinas-Riester G, Wiltfang J, Klafki HW, Wirths O. Physical activity delays hippocampal neurodegeneration and rescues memory deficits in an Alzheimer disease mouse model. Transl Psychiatry. 2016;6:e800.

34. Bednarek E, Caroni P. Beta-Adducin is required for stable assembly of new synapses and improved memory upon environmental enrichment. Neuron. 2011:69:1132-46.

35. Jankowsky JL, Xu G, Fromholt D, Gonzales V, Borchelt DR. Environmental enrichment exacerbates amyloid plaque formation in a transgenic mouse model of Alzheimer disease. J Neuropathol Exp Neurol. 2003;62:1220-7. 
36. Cotel MC, Jawhar S, Christensen DZ, Bayer TA, Wirths O. Environmental enrichment fails to rescue working memory deficits, neuron loss, and neurogenesis in APP/PS1KI mice. Neurobiol Aging. 2012;33:96-107.

37. Gomes da Silva S, de Almeida AA, Fernandes J, Lopim GM, Cabral FR, Scerni DA, de Oliveira-Pinto AV, Lent R, Arida RM. Maternal Exercise during Pregnancy Increases BDNF Levels and Cell Numbers in the Hippocampal Formation but Not in the Cerebral Cortex of Adult Rat Offspring. PLoS One. 2016;11:e0147200

38. Phillips HS, Hains JM, Armanini M, Laramee GR, Johnson SA, Winslow JW. BDNF mRNA is decreased in the hippocampus of individuals with Alzheimer's disease. Neuron. 1991;7:695-702.

39. Peng S, Wuu J, Mufson EJ, Fahnestock M. Precursor form of brain-derived neurotrophic factor and mature brain-derived neurotrophic factor are decreased in the pre-clinical stages of Alzheimer's disease. J Neurochem. 2005:93:1412-21.

40. Qin XY, Cao C, Cawley NX, Liu TT, Yuan J, Loh YP, Cheng Y. Decreased peripheral brain-derived neurotrophic factor levels in Alzheimer's disease: a meta-analysis study ( $\mathrm{N}=7277$ ). Mol Psychiatry. 2017;22:312-20.

41. Song JH, Yu JT, Tan L. Brain-derived neurotrophic factor in Alzheimer's disease: risk, mechanisms, and therapy. Mol Neurobiol. 2015;52:1477-93.

42. Lu B, Nagappan G, Guan X, Nathan PJ, Wren P. BDNF-based synaptic repair as a disease-modifying strategy for neurodegenerative diseases. Nat Rev Neurosci. 2013;14:401-16.

43. Buchman AS, Yu L, Boyle PA, Schneider JA, De Jager PL, Bennett DA. Higher brain BDNF gene expression is associated with slower cognitive decline in older adults. Neurology. 2016;86:735-41.

44. Kazim SF, Iqbal K. Neurotrophic factor small-molecule mimetics mediated neuroregeneration and synaptic repair: emerging therapeutic modality for Alzheimer's disease. Mol Neurodegener. 2016;11:50.

45. Wu Y, Luo X, Liu X, Liu D, Wang X, Guo Z, Zhu L, Tian Q, Yang X, Wang JZ. Intraperitoneal Administration of a Novel TAT-BDNF peptide ameliorates cognitive impairments via modulating multiple pathways in two Alzheimer's rodent models. Sci Rep. 2015;5:15032.

46. Chen C, Wang Z, Zhang Z, Liu X, Kang SS, Zhang Y, Ye K. The prodrug of 7,8-dihydroxyflavone development and therapeutic efficacy for treating Alzheimer's disease. Proc Natl Acad Sci U S A. 2018:115:578-83.

47. Zhang Z, Liu X, Schroeder JP, Chan CB, Song M, Yu SP, Weinshenker D, Ye K. 7,8-dihydroxyflavone prevents synaptic loss and memory deficits in a mouse model of Alzheimer's disease. Neuropsychopharmacology. 2014;39: 638-50.

48. Wang ZH, Wu W, Kang SS, Liu X, Wu Z, Peng J, Yu SP, Manfredsson FP, Sandoval IM, Liu X, et al. BDNF inhibits neurodegenerative diseaseassociated asparaginyl endopeptidase activity via phosphorylation by AKT. JCl Insight. 2018;3.

49. Aid T, Kazantseva A, Piirsoo M, Palm K, Timmusk T. Mouse and rat BDNF gene structure and expression revisited. J Neurosci Res. 2007;85:525-35.

50. Mychasiuk R, Zahir S, Schmold N, Inytskyy S, Kovalchuk O, Gibb R. Parental enrichment and offspring development: modifications to brain, behavior and the epigenome. Behav Brain Res. 2012;228:294-8.

51. Palomer E, Martin-Segura A, Baliyan S, Ahmed T, Balschun D, Venero C, Martin MG, Dotti CG. Aging triggers a repressive chromatin state at Bdnf promoters in hippocampal neurons. Cell Rep. 2016;16:2889-900.

52. Palomer E, Carretero J, Benvegnu S, Dotti CG, Martin MG. Neuronal activity controls Bdnf expression via Polycomb de-repression and CREB/CBP/JMJD3 activation in mature neurons. Nat Commun. 2016;7:11081.

53. Fuchikami M, Yamamoto S, Morinobu S, Takei S, Yamawaki S. Epigenetic regulation of BDNF gene in response to stress. Psychiatry Investig. 2010;7: 251-6.

54. Neidl R, Schneider A, Bousiges O, Majchrzak M, Barbelivien A, de Vasconcelos AP, Dorgans K, Doussau F, Loeffler JP, Cassel JC, Boutillier AL. Late-life environmental enrichment induces acetylation events and nuclear factor kappaB-dependent regulations in the Hippocampus of aged rats showing improved plasticity and learning. J Neurosci. 2016;36:4351-61.

55. Kaplan DR, Miller FD. Neurotrophin signal transduction in the nervous system. Curr Opin Neurobiol. 2000;10:381-91.

56. Brunet A, Datta SR, Greenberg ME. Transcription-dependent and -independent control of neuronal survival by the PI3K-Akt signaling pathway. Curr Opin Neurobiol. 2001;11:297-305.

57. Wang Q, Liu L, Pei L, Ju W, Ahmadian G, Lu J, Wang Y, Liu F, Wang YT. Control of synaptic strength, a novel function of Akt. Neuron. 2003;38: 915-28.
58. Yoshii A, Constantine-Paton M. BDNF induces transport of PSD-95 to dendrites through PI3K-AKT signaling after NMDA receptor activation. Nat Neurosci. 2007;10:702-11.

59. Zubenko GS, Stiffler JS, Hughes HB, Martinez AJ. Reductions in brain phosphatidylinositol kinase activities in Alzheimer's disease. Biol Psychiatry. 1999;45:731-6.

60. Kim W, Noh H, Lee Y, Jeon J, Shanmugavadivu A, McPhie DL, Kim KS, Cohen BM, Seo H, Sonntag KC. MiR-126 regulates growth factor activities and vulnerability to toxic insult in neurons. Mol Neurobiol. 2016;53:95-108.

61. Jimenez S, Torres M, Vizuete M, Sanchez-Varo R, Sanchez-Mejias E, TrujilloEstrada L, Carmona-Cuenca I, Caballero C, Ruano D, Gutierrez A, Vitorica J. Agedependent accumulation of soluble amyloid beta (Abeta) oligomers reverses the neuroprotective effect of soluble amyloid precursor protein-alpha (sAPP (alpha)) by modulating phosphatidylinositol 3-kinase (PI3K)/Akt-GSK-3beta pathway in Alzheimer mouse model. J Biol Chem. 2011;286:18414-25.

62. Baki L, Shioi J, Wen P, Shao Z, Schwarzman A, Gama-Sosa M, Neve R, Robakis NK. PS1 activates PI3K thus inhibiting GSK-3 activity and tau overphosphorylation: effects of FAD mutations. EMBO J. 2004;23:2586-96.

63. Lucas JJ, Hernandez F, Gomez-Ramos P, Moran MA, Hen R, Avila J. Decreased nuclear beta-catenin, tau hyperphosphorylation and neurodegeneration in GSK-3beta conditional transgenic mice. EMBO J. 2001; 20:27-39.

64. Rohe M, Synowitz M, Glass R, Paul SM, Nykjaer A, Willnow TE. Brain-derived neurotrophic factor reduces amyloidogenic processing through control of SORLA gene expression. J Neurosci. 2009;29:15472-8.

65. Nigam SM, Xu S, Kritikou JS, Marosi K, Brodin L, Mattson MP. Exercise and BDNF reduce Abeta production by enhancing alpha-secretase processing of APP. J Neurochem. 2017;142:286-96.

66. Erickson Kl, Voss MW, Prakash RS, Basak C, Szabo A, Chaddock L, Kim JS, Heo $\mathrm{S}$, Alves $\mathrm{H}$, White $\mathrm{SM}$, et al. Exercise training increases size of hippocampus and improves memory. Proc Natl Acad Sci U S A. 2011;108:3017-22.

67. ten Brinke LF, Bolandzadeh N, Nagamatsu LS, Hsu CL, Davis JC, Miran-Khan K, Liu-Ambrose T. Aerobic exercise increases hippocampal volume in older women with probable mild cognitive impairment: a 6-month randomised controlled trial. Br J Sports Med. 2015;49:248-54.

68. Colcombe SJ, Erickson KI, Scalf PE, Kim JS, Prakash R, McAuley E, Elavsky S, Marquez DX, Hu L, Kramer AF. Aerobic exercise training increases brain volume in aging humans. J Gerontol A Biol Sci Med Sci. 2006;61:1166-70.

69. Lautenschlager NT, Cox KL, Flicker L, Foster JK, van Bockxmeer FM, Xiao J, Greenop KR, Almeida OP. Effect of physical activity on cognitive function in older adults at risk for Alzheimer disease: a randomized trial. JAMA. 2008; 300:1027-37.

70. Valenzuela M, Sachdev P. Can cognitive exercise prevent the onset of dementia? Systematic review of randomized clinical trials with longitudinal follow-up. Am J Geriatr Psychiatry. 2009;17:179-87.

71. Hopkins SA, Baldi JC, Cutfield WS, McCowan L, Hofman PL. Effects of exercise training on maternal hormonal changes in pregnancy. Clin Endocrinol. 2011;74:495-500.

72. Clapp JF 3rd. Morphometric and neurodevelopmental outcome at age five years of the offspring of women who continued to exercise regularly throughout pregnancy. J Pediatr. 1996;129:856-63.

73. Nino Cruz Gl, Ramirez Varela A, da Silva ICM, Hallal PC, Santos IS. Physical activity during pregnancy and offspring neurodevelopment: a systematic review. Paediatr Perinat Epidemiol. 2018;32:369-79.

74. Jukic AM, Lawlor DA, Juhl M, Owe KM, Lewis B, Liu J, Wilcox AJ, Longnecker MP. Physical activity during pregnancy and language development in the offspring. Paediatr Perinat Epidemiol. 2013;27:283-93.

75. Vega SR, Kleinert J, Sulprizio M, Hollmann W, Bloch W, Struder HK Responses of serum neurotrophic factors to exercise in pregnant and postpartum women. Psychoneuroendocrinology. 2011;36:220-7.

76. Hertze J, Nagga K, Minthon L, Hansson O. Changes in cerebrospinal fluid and blood plasma levels of IGF-II and its binding proteins in Alzheimer's disease: an observational study. BMC Neurol. 2014;14:64.

77. McLimans KE, Webb JL, Anantharam V, Kanthasamy A, Willette AA. Alzheimer's disease neuroimaging I: peripheral versus central index of metabolic dysfunction and associations with clinical and pathological outcomes in Alzheimer's disease. J Alzheimers Dis. 2017;60:1313-24.

78. Talbot K, Wang HY, Kazi H, Han LY, Bakshi KP, Stucky A, Fuino RL, Kawaguchi KR, Samoyedny AJ, Wilson RS, et al. Demonstrated brain insulin resistance in Alzheimer's disease patients is associated with IGF-1 resistance, IRS-1 dysregulation, and cognitive decline. J Clin Invest. 2012;122:1316-38. 
79. Vidal JS, Hanon O, Funalot B, Brunel N, Viollet C, Rigaud AS, Seux ML, leBouc Y, Epelbaum J, Duron E. Low serum insulin-like growth factor-I predicts cognitive decline in Alzheimer's disease. J Alzheimers Dis. 2016;52: $641-9$.

80. Carro E, Trejo JL, Busiguina S, Torres-Aleman I. Circulating insulin-like growth factor I mediates the protective effects of physical exercise against brain insults of different etiology and anatomy. J Neurosci. 2001;21:5678-84.

81. Carro E, Nunez A, Busiguina S, Torres-Aleman I. Circulating insulin-like growth factor I mediates effects of exercise on the brain. J Neurosci. 2000: 20:2926-33.

82. Ciucci F, Putignano E, Baroncelli L, Landi S, Berardi N, Maffei L. Insulin-like growth factor 1 (IGF-1) mediates the effects of enriched environment (EE) on visual cortical development. PLoS One. 2007;2:e475.

83. Baldini S, Restani L, Baroncelli L, Coltelli M, Franco R, Cenni MC, Maffei L, Berardi N. Enriched early life experiences reduce adult anxiety-like behavior in rats: a role for insulin-like growth factor 1. J Neurosci. 2013;33:11715-23.

84. Wilson RS, Mendes De Leon CF, Barnes LL, Schneider JA, Bienias JL, Evans DA, Bennett DA. Participation in cognitively stimulating activities and risk of incident Alzheimer disease. JAMA. 2002;287:742-8.

85. Schaie KW. The Seattle longitudinal study: a thirty-five-year inquiry of adult intellectual development. Z Gerontol. 1993;26:129-37.

86. Shimamura AP. Memory and the prefrontal cortex. Ann N Y Acad Sci. 1995.

Ready to submit your research? Choose BMC and benefit from:

- fast, convenient online submission

- thorough peer review by experienced researchers in your field

- rapid publication on acceptance

- support for research data, including large and complex data types

- gold Open Access which fosters wider collaboration and increased citations

- maximum visibility for your research: over $100 \mathrm{M}$ website views per year

At $\mathrm{BMC}$, research is always in progress.

Learn more biomedcentral.com/submissions 